DOE/DP/70060--1

DE92 013738

\title{
RESEARCH AND DEVELOPMENT OF METHODS/UTILITIES AND RULES FOR MANAGING COOPERATION FOR PERFORMANCE IMPROVEMENT IN GOVERNMENT OFFICES
}

First Technical Progress Report

for period September 1, 1991 - August 31, 1992

Management Systems Laboratories

Virginia Polytechnic Institute and State University

Blacksburg, VA 24060-6353

March 1992

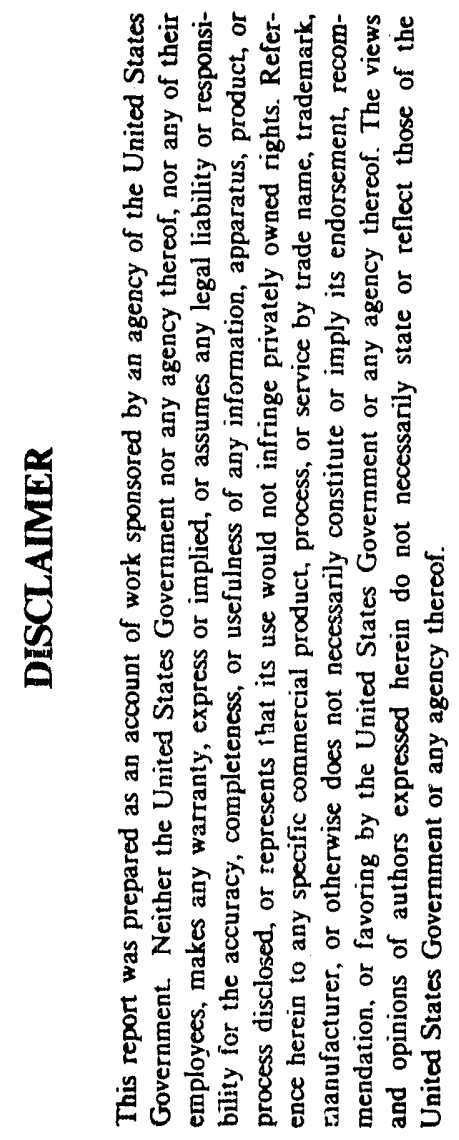

PREPARED FOR THE U.S. DEPARTMENT OF ENERGY UNDER GRANT NUMBER DE-FG05-91DP70060

Whind 


\section{Preface}

The Technical Progress Report is designed as a series of modules. Each module begins on the left, therefore blank pages appear in modules with an odd number of pages. 


\section{TABLE OF CONTENTS}

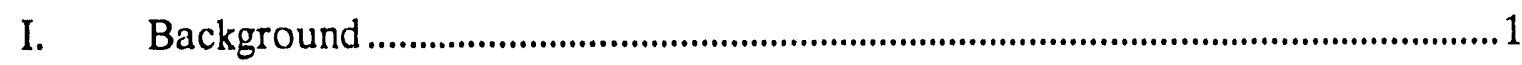

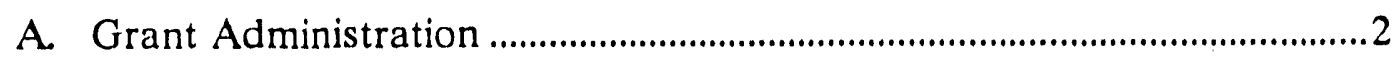

B. Purpose of the Grant ................................................................................

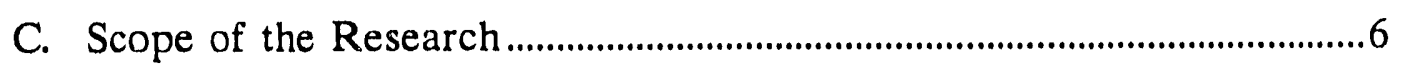

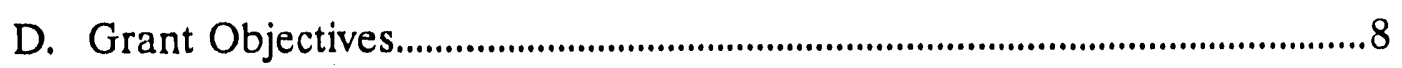

II. Research Studies..........................................................................................11

A. Research Conceptual Model........................................................................12

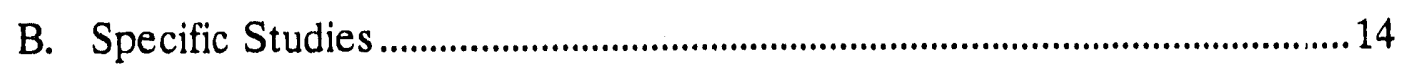

1. Information Management and Portrayal..................................................14

2. Identifying and Mapping Critical

Domain and Tool Characteristics.............................................................. 18

3. Improving the Software Development

Process for Creating Management Tools ...............................................22

4. Recruitment and Professional Development ..........................................26

5. Crisis Management...................................................................................

6. Culture Management ……………............................................................34

7. Manager/Management Tools Interface …………….................................36

8. Strategic Management ......................................................................... 40

9. Management Process ...................................................................................4

10. Risk Management....................................................................................... 46

11. Crisis Management in Projects ..................................................................48 


\section{LIST OF FIGURES}

Figure I.B.

Figure II.A.

Figure II.B.1.

Figure II.B.2.

Figure II.B.4.

Figure II.B.5.

Figure II.B.7.

Figure II.B.8.
Visibility and control principles and tools are the keys to reducing controllable brushfires and effectively dealing with uncontrollable brushfires. By keeping effort spent on brushfires within reasonable limits, managers then can use their initiative and ability for growth and improvement

The use of the nine management methods with their rules in developing design criteria for management tools affects the performance of the tools in managing components of an organization, and in turn, the overall performance of the organization.

Feedback from the Management System Model's (MSM) data-to-information process will inform the development of Management Tools/Interventions. Feedback from managers as they use those Management Tools/Interventions will in turn affect the MSM. This will impact how the GPO manages brushfires..

The effectiveness of tools in reducing brushfires should improve as a result of mapping problem domain and tool characteristics and using that information as a design criterion to tool development.

The Technical Training Management System consists of five interrelated components: Consensus Working Groups, Training System Plans, Career Planning, Technical Training, and Evaluation. Its implementation and the evaluation of its impact on organizational performance requires the development, use, and evaluation of appropriate management tools for recruitment and professional development.

Using unique tools designed for emergency management will permit managers to more quickly gain control of crises and spend more of their time improving the performance of the organization

It is important to apply a human factors view to a management system to understand the design of management tools.

The Deming PDSA Cycle can be combined with the consensus model to affect the strategic planning component within the GPO 


\section{APPENDICES}

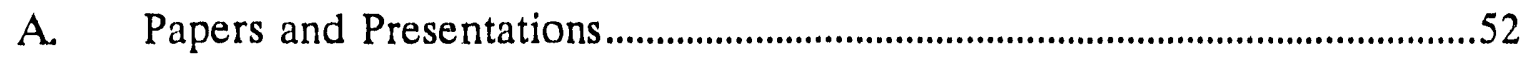

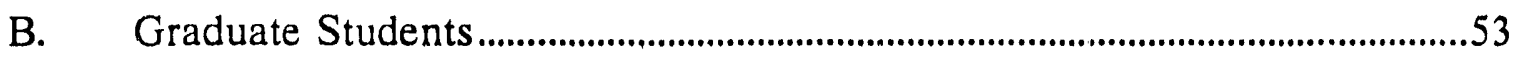

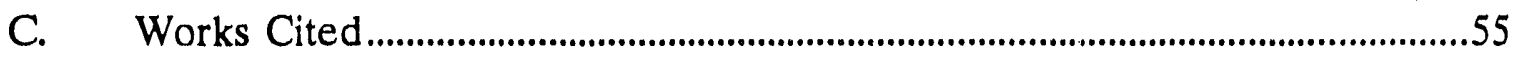




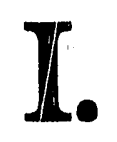

\section{Background}




\section{I.A. GRANT ADMINISTRATION}

On September 1, 1991, Defense Programs (DP) within the U.S. Department of Energy entered into a research grant with Management Systems Laboratories (MSL) of Virginia Polytechnic Institute and State University (Virginia Tech), to study Tools, Methods, and Rules for Managing Cooperation for Performance Improvement. The principal investigator, Dr. Harold A. Kurstedt, is the Hal G. Prillaman Professor of Industrial and Systems Engineering, Professor of Nuclear Engineering, and MSL's Director. The grant is based on a proposal entitled "Research and Development of Tools, Methods, and Rules for Managing Cooperation for Continuous Performance Improvement in Government Program Offices" (November 1990).

MSL is part of the Department of Industrial and Systems Engineering (ISE) in the College of Engineering at Virginia Tech and benefits from the facilities of the university and the expertise ar diverse perspectives of the faculty, stafi, and students. Because of its place in ISE, MSL can take advantage of these multiple resources to support or augment the MSL research team.

The organizational structure within MSL provides the research team with effective administrative and technical support. Senior-level management coordinates the work of program managers, project managers, graduate research assistants, and technical and support staffs. Senior managers provide a link between the grant sponsor, the university, and the research team.

Research findings are disseminated at professional meetings and in academic journals by members of the research team and by the graduate students working on the grant. Papers and presentations published or presented during the first five months of year one of the research grant appear in Appendix A.

Graduate students are important to the research of the grant and are important to MSL. Management Systems Engineering (MSE) is one of the graduate options within ISE. Engineering students interested in management typically enroll in the MSE option. During the first year of the grant we have four master's-level graduate students and one doctoral-level graduate student from the MSE option involved in research directly related to the grant. A complete list of graduate students involved directly or indirectly with the grant appears in Appendix B of this report.

The grant manager oversees the smooth operation of all phases and sysisms academic, administrative, and financial pertaining to the grant. The program manager in each program group is assisted by project managers, research associates, graduate students, and technical and support staff who plan, manage, monitor, and carry out the work in the study areas appearing in this report. Each program group becomes a research team working together to 
define and meet the research objectives of its specific study areas.

The Internal Accounting System is set up to manage and track the finances of a research program. The system was specifically designed and produced to meet the special requirements of managing multiple, task-oriented programs, and it produces monthly financial reports. This allows direct monthly communication between research task managers and the specific sponsor, as well as providing a monthly summary of research accomplishments for the technical represintatives of the sponsoring organizations.

This in-house system allows the research team to track the different studies. Each research task manager can create and monitor a budget built around the people, study area, and equipment. Maintaining and using an internal financial management system allows more timely and flexible reporting than could be accomplished using the university system alone.

Our technical progress report describes our research efforts during the first five months of grant year one. To meet the reporting deadline, the content of our First Technical Progress Report covers the period ending Januriry 31, 1992. Since our grant started on September 1 , 1991, our grant year and reporting year overlap by five months.

As a consequence of the overlap between grant and reporting cycles, future technical progress reports will describe our performance for the first five months of the current year in addition to reporting on the remaining seven months of the prior year. For example, the Second Technical Progress Report will cover the period February 1, 1992 through January 31, 1993. 


\section{I.B. PURPOSE OF THE GRANT}

We want to help managers approach their responsibilities proactively so they can anticipate problems and take actions to alleviate or eliminate those problems. More than they would like to, managers react to their environment. They have more problems than they can possibly address, so they only address the most pressing ones, which are not always the most important ones. They often only have time to attend to the problems that have escalated to the point of requiring their immediate attention. Managers need and want help to surface problems while those problems are sparks--before they become brushfires. We want to help them do that through mechanisms based on the principles of visibility and control.

Most managers have the willingness to manage proactively, yet they lack the means. They are hampered by a workplace that constantly calls for their immediate attertion and sacrifices the long-term for the short-term. If they only had better ways of detecting sparks at their inception, they would be better prepared to mitigate surprises and deal with them once they occur.

We want to find a new approach to help managers better respond to surprises (or brushfires) rather than having to react to them. To help managers better respond, this new approach must identify crucial indicators of performance and monitor those indicators in such a way that managers at various levels in the organization can share information and coordinate their expectations, actions, and evaluations. This approach must not only deal effectively with information but, most importantly, deal effectively with cooperation based on that information.

Managers who want to manage proactively and find and eliminate potential problems must know what they have to do, do it, and know they did it well. A new management approach (or a new understanding of management principles and tools not now used effectively or proactively) will inelp managers take control of their day and spend their time wisely. It will reduce the number and impact of brushfires and free up time for managers to use their creative talents.

Visibility implies knowing how everything in a system ties together--relating the causes to their effects. Control means to hold something constant or direct it toward desired outcomes, so the manager knows what to expect. To gain visibility and control, managers want to know, as shown in Figure I.B, what to do and how to do it well. To achieve our stated purpose for this research, we must determine why the principles behind certain tools, methods, and rules work well in an organization, so that organizations now doing well can continue to do so and organizations not doing so well can do better.

Our hypothesis in Figure I.B is that the key to managers knowing what to du, doing it well, and knowing they did it well is having effective means for gaining visibility and control. Tools and methods can be assembled and aimed directly at visibility and control. When these tools and methods are guided by the right rules, managers can reduce 
brushfires to the point of gaining the time they need for growth and improvement in the products or services they provide to their stakeholders.

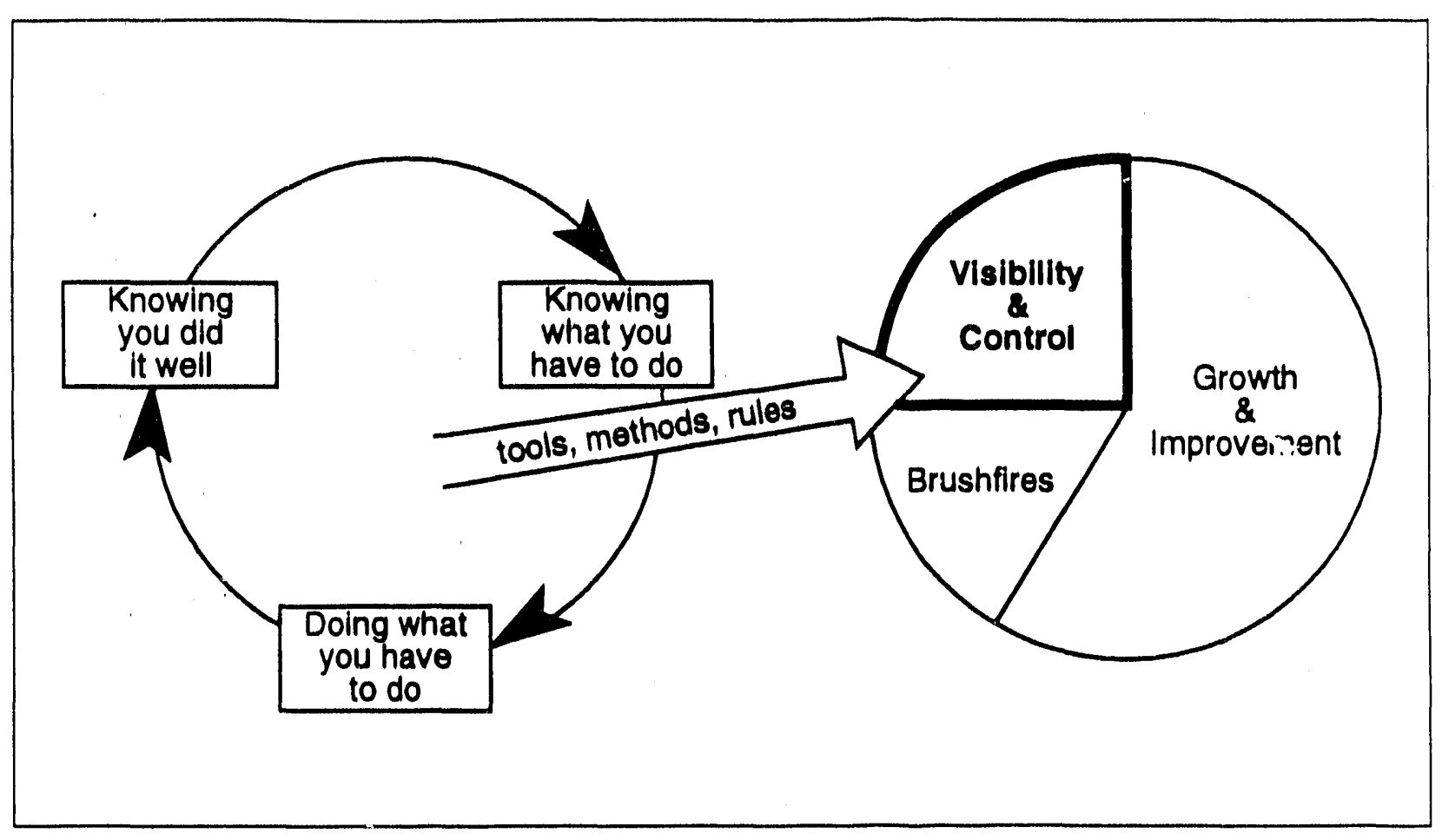

Figure I.B.

Visibility and control principles and tools are the keys to reducing controllable brushfires and effectively dealing with uncontrollable brushïres. By keeping effort spent on brushfires within reasonable limits, managers then can use their initiative and ability for growth and improvement. 


\section{I.C. SCOPE OF THE RESEARCH}

Continuous performance improvement is a gradual, systematic process. The idea is to do a little better each day by knowing where you are, where you want to be, what you have to do to get there, whether or not you have done it, and how to resolve problems doing it. And, although many management decisions are made along direct lines of authority, much of the work of an organization can be achieved only through cooperation (people sharing information and coordinating effort). Therefore, continuous performance improvement requires working cooperatively to do a little better each day.

Continuous performance improvement is the philosophy behind total quality management. By discovering and using an effective management process, we design in quality. The only way to design in quality is to have a quality management process. Typical management techniques often fail because they address only a part of the process or lack the flexibility required for changing organizational environments. What is needed is a comprehensive package of management tools that can be selected and adapted to effectively address various decisionmaking environments.

We are researching the most effective configuration of tools working througn what we believe is a closed set of nine methods. These methods are: setting expectations, charting, defining indicators and standards, collecting and logging data, converting data to information, organizing and presenting information, reviewing status and progress, self- management, and appraising. We believe that these methods form a closed set because they reflect the management activities of formulation (planning), execution (doing), and verification (evaluating). If these activities are carried out effectively through the methods, the manager can achieve visibility and control.

In addition to these nine methods, there are eight rules - the soul of the process. Working individually and collectively, they guide and complement the methods to achieve balance and syriergy. The rules that we believe are of particular importance to government program offices are: Focus on what you can do. Supply physical evidence of progress. Pay attention to detail. Inspect, don't expect. Review progress routinely and frequently. Face "success/fail" squarely. Communicate crisply. Conduct honest, open appraisals.

The tools are the part of the structured management process that managers will experience and use most. The tools are the focus of our research efforts. We are determining criteria for improving tools so that they provide managers with needed information. We will determine the success of the tools in providing that information and determine why a particular tool works or fails in a certain decision-making environment.

As we originally proposed, much of our efforts in the first reporting period have concentrated on completing a draft of our research plan to guide our efforts throughout the life of the grant. To plan our efforts, we have focused on 
understanding the specific needs and situations within Defense Programs and have begun formalizing our knowledge of previous research from the scientific literature. The content of this plan is reflected in section II, where we describe the scope and plans of the study areas.

Our research efforts span a five year period. During this time, we will conduct many types of studies, including exploratory, qualitative, confirmatory, and quantitative research.

We will investigate the relervant scientific and practical bodies of knowledge, conduct research investigations, integrate our results with past knowledge to draw conclusions, and disseminate those conclusions through publications and presentations. 


\section{L.D. GRANT OBJECTIVES}

To achieve the purpose of this grant as discussed in section I.B, our research is aimed at determining why certain tools, methods, and rules work well in an organization. Our goal is to discover and formalize the conceptual basis of methods through which rnanagement tools work to get the right information. Taken together, these methods and the rules that guide their use should form a management process for people to use cooperatively in gaining visibility and control.

Academic and practical objectives create dual goals for our research. Academic objectives enable the research to contribute to the body of knowledge. Practical objectives guide the research to maximize the potential for benefits to the sponsor.

With our academic objectives we aim to understand and demonstrate: 1) how externally-caused and internally-induced brushfires affect managers and their performance; 2 ) what rules, methods, and tools managers need to implement the management process; 3 ) how to skillfully use the methods and tools to implement a management process; 4) the principles behind the rules, methods, and tools that work and behind the cause and efictionships among the rules, methods, and tools; 5) the ability to generalize from these principles and underlying theories to a range of organizations with a range of responsibilities.

The following practical objectives highlight research outcomes:
1. Use selected government program offices (GFOs) of the Department of Energy as the real world laboratory to define, characterize, implement, improve, manage, test, and demonstrate the effects of the principles behind rules, miethods, and tools, specifically recognizing the unique qualities of managing recurring organizational brushfires for maintaining stability and achieving progress in a GPO.

2. Learn and understand the causes of brushfires (crises that preempt managers' time by unnecessarily attracting negative attention and focising on past problems) and find ways to avoid or control them.

3. Study, design, develop, observe, and refine methods and tools for managers to monitor and manage their organizations and mechanisms for disseminating these methods and tools in a tangible, comprehensive, integrated package to demonstrate to managers that they can control brushfires by improving their processes.

4. Understand the causes of synergy among the rules, methods, and tools and discover ways to enhance that synergy and the value of the synergy to the manager.

5. Measure the sensitivity of reducing the number and impact of brushfires on tools and combinations of tools.

6. Understand, document, and support interactions among interdependent 
organizations by giving managers rules, methods, and tools to reduce the impact of externally-caused brushfires and reduce the number of internally-induced brushfires occurring in GPOs.

7. Facilitate and observe the coordination and integration of efforts among multiple layers of responsibility--headquarters, field sites, and other organizations--for deriving empirical generalizations.

8. Hypothesize and test a working management process for surfacing and dealing with early indications of problems within interdependent organizations reporting to (or supervising the activities of) other organizations.

9. Define and study the required roles and responsibilities for the integration of organizations, groups, and individuals in effectively developing and implementing a package of rules, methods, and tools for early problem detection and resolution.

10. Demonstrate to managers that improved tools, methods, and rules can help them respond more effectively to rapid changes in their environment. 


\section{II.}

\section{Research Studies}




\section{II.A. RESEARCH CONCEPTUAL MODEL}

A research conceptual model guides and directs all research efforts within a research program. It delineates the scope of the variables that are being studied and globally illustrates the hypothesized relationships among those variables. As suchi, specific studies can be identified which test one or more of the hypothesized relationships. The research conceptual model, therefore, indicates where data are needed, implies suitable data analysis, and provides the guiding principles for the interpretation of the data.

As discussed in the proposal, a manager's activities can be categorized into three groups: (A) administering the management process (or gaining visibility and control), (B) building the organization and improving performance, and $(\mathrm{C})$ catering to crises (or fighting brushfires). If a manager spends more time doing " $\mathrm{A}$ " better, then " $\mathrm{C}$ ", the time spent dealing with brushfires, will be reduced, and the manager will have more time to do "B", build the organization and continually improve the products or services it provides to the stakeholders. The key to doing "A", gaining visibility and control, is the application of properly designed management tools. The manager cannot gain the visibility and control needed with a poorly chosen set of management tools. We believe a set of nine methods with their rules should guide the design of management tools, providing a structured management process. The basis for these nine methods lies in the principle of the control theory feedback loop. By implementing a structured management process, managers are better able to allocate their time in managing their responsibilities in the organization. With more time to spend coordinating their people on "B," building the business activities, the organization will be better postured to achieve continuous performance improvement.

Figure II.A illustrates the research conceptual model. As shown by the solid arrows, a manager uses the output from management tools to make decisions which affect components within the organization (depicted by the small circles within the government program office), which in turn affect the overall performance of the organization. The management tools must not only be based upon sound design criteria derived from the management methods and rules, but must also be based on information regarding the specific needs and conditions within the organization. The tools should also be evaluated within the organization, as illustrated by the feedback loops (i.e., the dashed lines) in the figure. We hypothesize that without a structured management process based on the nine management methods and their rules, managers' tcols will provide insufficient information to adequately manage their domain. As such, managers and tỉeir staffs will spend much of their time fighting brushfires within the organization rather than cooperatively working on performance improvement activities. The performance of the components, and hence the overall performance of tiie organization, will suffer. 
If, on the other hand, managers use customized management tools based on the nine management methods with their rules, they will spend more time gaining visibility and control. As a result, the number and severity of brushfires will be reduced, leaving more time available for everyone to cooperatively work on performance improvement activities within the various components of the organization. Hence, the organization as a whole will be better able to achieve continuous performance improvement.

We will study how the use of the nine management methods with their rules in developing design criteria for management tools affects the performance of the tools in managing components of an organization, and in turn, the overall performance of the organization.

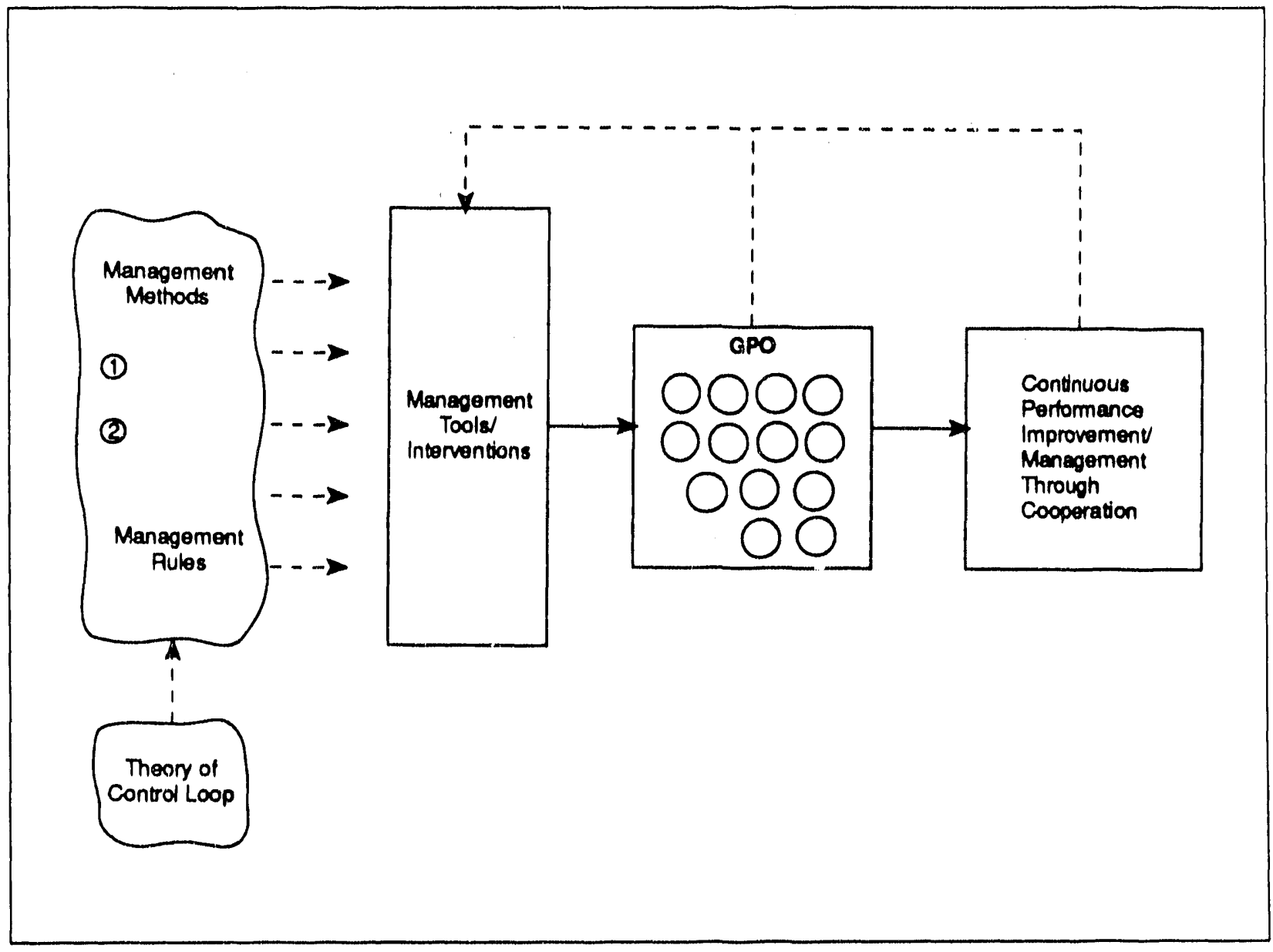

Figure II.A.

The use of the nine management methods with their rules in developing design criteria for management tools affects the performance of the tools in managing components of an organization, and in turn, the overall performance of the organization. 


\section{II.B.1. INFORMATTON MANAGEMENT AND PORTRAYAL}

\section{a. Study Area Leader(s)}

Howard Swingle

Sheila Winett

\section{b. Description of Study Area}

The information management and portrayal study area focuses on understanding how management tools and their users interact. Tools and their users interact through information (the tool's product) and interface (how the tool delivers the product). Data (the "source material" used by the tool to build the product) indirectly influence how tools interact with users.

This study area strives to understa: $d$ the roles played by information, data, and interface in the interaction between tools and users. We will pursue research in three topic areas: 1) information needs analysis, 2) managing the data resource, and 3 ) information portraval techniques.

Our research in the first topic area, information needs analysis, will investigate ways to identify what information users need. We will also explore how management tools can help fill identified information needs.

Research related to managing the data resource, our second topic area, will look for ways to manage the "source material" so tools deliver the right information. Research on our third topic area, information portrayal techniques, will attempt to determine how tools can best present information to users.

This research is based on the idea that information is data about indicators and standards that are transforrned and portrayed in ways that allow managers to assess performance of a government program office (GPO). Indicators are measurable items that tell about the performance of the LPO. Standards are ideal, desired, or acceptable values for each indicator. If an indicator meets or exceeds the standard, the GPO is performing the way the manager wants.

In a management process, if managers set the right indicators and standards (as part of this process), they can avoid or reduce the impact of brushires. Once indicators and standards are set, the manager uses management tools to collect data about each indicator, convert data to information, and organize and present the information. The manager reviews status and progress using the information. This study area looks at how managers interact with management tools to collect data, convert data to information (using algorithms), and organize and present information.

\section{c. Relatiouship to the Research Conceptual Model}

Figure II.B.1 shows the relationship between the Management System Model and the Management Tools/Interventions part of the research conceptual model. The Management System Model (MSM) shows hu.e tools ("what is used to manage") ge $i$ data, convert data into information, and present information, via an interface, to the manager ("who manages"). Managers then make decisions about their domains of 
responsibility ("what is managed") based on that information.

Within the MSM, management tools mediate between the data/measurement interface and the information portrayal/perception interface. The MSM data-to-information process will provide the basis for identifying information needs, managing the data resource, and determining how tools can best portray information. Conversely, feedback from users of the Management Tools/Interventions visualized in the research conceptual model will affect the MSM data-to-information process. As a result of this interchange, we will be able to construct more appropriate tools for GPO managers and positively impact the GPO. As we implement these tools in the GPO, we expect thi.t brushfires will be reduced and the overall performance of the organization will improve.

\section{d. Accomplishments}

\section{Information Needs Analysis}

As a preliminary step in our information needs analysis research, we have studied the Defense Programs (DP) organization to better understand the information needs of its managers. We have focused on understanding what DP manages and the issues and conditions that constrain its managers. We have accomplished this primarily by closely observing our sponsors, participating in the Department of Energy material management committee meetings, and performing analyses of "what-if" cases.

To collect data about information needs associated with strategic materials planning, for exampie, we attended the weekly materials planning task force meetings. To help identify potential effects on plutonium management issues, we performed an analysis of a "what-if" scenario based on one planning case. We also analyzed eight "what-if" tritium supply and demand cases to learn about the data needed to conduct those analyses and to informally assess the information portrayal techniques available using current management tools. Based on our observations we'll initiate exploratory studies to identify effective approaches to determining information needs and identifying tools that may help the needs assessment task.

\section{Managing the Data Resource}

Our preliminary efforts to find ways to manage the data resource have been twofold. We have evaluated existing tools to find methods and features that work. Then, to test our initial findings about existing tools and observe the effects of new tools, we developed and introduced tools that we believed would improve data access, manipulation, and accuracy.

With stockpile management, for example, we implemented a tool that easily imports available stockpile data into any spreadsheet application so managers can do ad hoc analyses of "what-if" cases. To help managers better interpret case differences, we have provided comparison utilities to both stockpile and tritium managers. And, to improve data sharing, we gave tritium managers a utility that downloads results from the Albuquerque Master Nuclear Schedule and converts them to a form usable by the Tritium Personal Computer Master Nuclear Schedule. Following these interventions, we observed the effects of each on the ability of managers to control and/or respond effectively to brushfires. We will use our observational data to plan future research interventions. 
Information Portraval Techniques

Evaluating existing tools and developing and introducing tools has also allowed us to identify information portrayal techniques that work for DP managers. We have concentrated on studying features that we think will help managers conduct analyses more easily and efficiently and provide information that is easier to interpret. To observe whether changing the interface of a tool would affect a manager's analysis efficiency, we have enhanced existing tools to improve the way DP managers must navigate to accomplish frequently performed tasks. We have also studied and changed the way data are portrayed in some management tools to see if alternative portrayal features would make analyses easier to understand.

In strategic materials planning, for example, to informally observe the usefulness of certain tool features, we added enhancements that highlight negative forecasted inventories, allow graphic data portrayal, and provide better error checking capabilities. In uranium management we have enhanced data portrayal by providing multiple views of the same input data, and we have begun exploring techniques for simplifying information selection through progressive disclosure. We also developed a new Stockpile Improvement Program Analysis System to allow DP managers to easily see whether planned stockpile conversion scenarios are feasible. We then observed whether having that tool helped DP managers create more accurate stockpile cases.

Based on lessons learned thus far by observing DP managers in the organization and the environment in which they must manage, we have been able to formulate some potential research questions in each topic area in which we intend to pursue research.

For example, in the information needs analysis topic area, questions about the processes and tools needed to determine new indicators, standards, and algorithms, and the role of data cost and data value in determining what data to collect have been identified as potentially useful. Questions related to tool features that may help maintain data integrity and consistency and tool features that balance data consistency and accuracy are both researchable in the area of managing the data resource. The information portrayal techniques area is also rich with research possibilities that we have begun to identify.

We expect to work with DP managers through the end of the first grant year to continue learning their specific needs. We will continue to evolve on our initial research questions and define our research plans for subsequent grant years. 


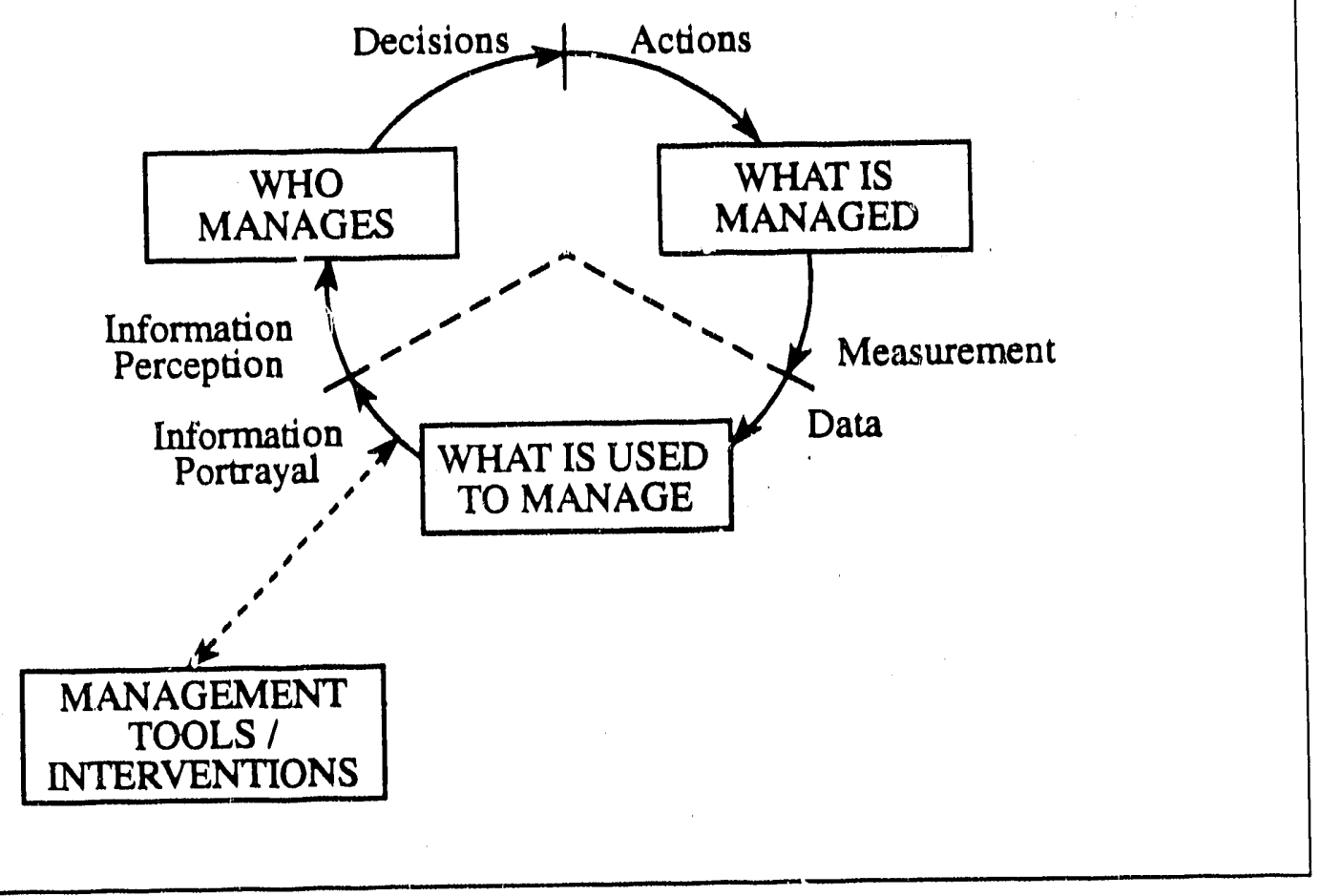

Figure II.B.1. Feedback from the Management System Model's (MSM) data-toinformation process will inform the development of Management Tools/Interventions. Feedback trom managers as they use those Management Tools/Interventions will in turn affect the MSM. This will impact how the GPO manages brushfires. 


\section{II.B.2. IDENTIFYING AND MAPPING CRITICAL DOMAIN AND TOOL CHARACTERISTICS}

\section{a. Study Area Leader(s)}

Howard Swingle

Sheila Winctt

\section{b. Description of Study Area}

T'o help a government program office (GPCI) manager effectively deal with brushfires, it is not sufficient to have a management tool that presents the "right" data in the "right" way. To be effective, the tool must also incorporate qualities or characteristics that match the environment in which it will be used. For example, in a rapidly changing environment, management tools should be flexible or robust enough to meet the changing information needs of GPO managers.

In the past, it was sufficient to iteratively define the management tool needed by a GPO manager. Through an evolutionary process, a tool with the "right" characteristics--those that matched the challenges presented by the problem domain--would be developed. Now, however, because the Department of Energy is undergoing rapid change, the useful life of a tool may be quite short. A tool may only be used for a few weeks before the requirements change and a new tool is needed or the tool must be changed dramatically to meet new information needs.

To respond more quickly in a rapidly changing environment, it is critical to find better (faster) ways to identify and map tool characteristics that match the domain. Therefore, our research in this study area focuses on identification of tool and problem domain characteristics, and development of a systematic approach to mapping problem domain characteristics to important tool characteristics.

Our "test case" problem domain will be Defense Programs (DP) managers and their GPO environment, with special emphasis on the impact of rapid organizational change on information requirements and needs. For example, critical characteristics of this prublem domain may be: "need to merge information from multiple sources," "highly consistent information is more important than highly accurate information," "reduced level of detail is acceptable," "time-frame analyzed must be flexible," or "data sources may change rapidly."

The effectiveness of tools will be researched and evaluated to see if they help managers better deal with brushfires. Furthermore, we will try to determine the tool characteristics that are most critical to effectiveness. Some that we may investigate are "highly flexible through user-configuration," "discrete components that can be linked together," or even "highly detailed but difficult to learn."

Our research should suggest processes for identifying and mapping problem domain and tool characteristics that lead to development of effective management tools. 


\section{c. Relationship to the Research Conceptual Model}

Our research aims to make GPO managers more effective by reducing the impact of brushfires. To do this, the characteristics of the GPO (problem domain) environment must be identified and mapped to tool characteristics. Figure II.B.2 illustrates how we conceptualize the mapping process.

The effectiveness of the tools in addressing the critical characteristics of the GPO environment can be evaluated in the short- and long-term. Evaluation results provide feedback to guide development of improved tools. By providing tools that are tailored to the organization's critical characteristics, we believe we can positively affect the performance of DP managers and limit the impact of brushfires. Our research conceptual model shows that as we change the way managers respond to and manage brushfires, we expect the overall performance of the organization to continuously improve.

\section{d. Accomplishments}

During the first grant year, we have been observing and collecting data on selected DP managers to become familiar with their problem domain environments. We have begun to identify domain characteristics common to the environments that DP managers work in and domain characteristics that may be unique to an individual manager. We have also begun to identify and study characteristics if different management tools already used by the managers and current information needs and requirements.

We have studied ways to help managers predict internal and external changes that may have implications for the kinds of information they may need to manage in the firt"... We have informally evalua. i some existing tools by observing managers as they use them and asking questions such as: Are the answers you're getting "right"? How does using this tool help you manage and reduce brushfires? As a rerult, we have collected data that will enable us to start identifying critical characteristics of current tools and the relationship that those may have to tool effectiveness.

We expect to continue observing DP managers through the rest of the first grant year. We will use our observations to formulate research questions and hypotheses during the second grant year and begin exploratory studies in this research area. 


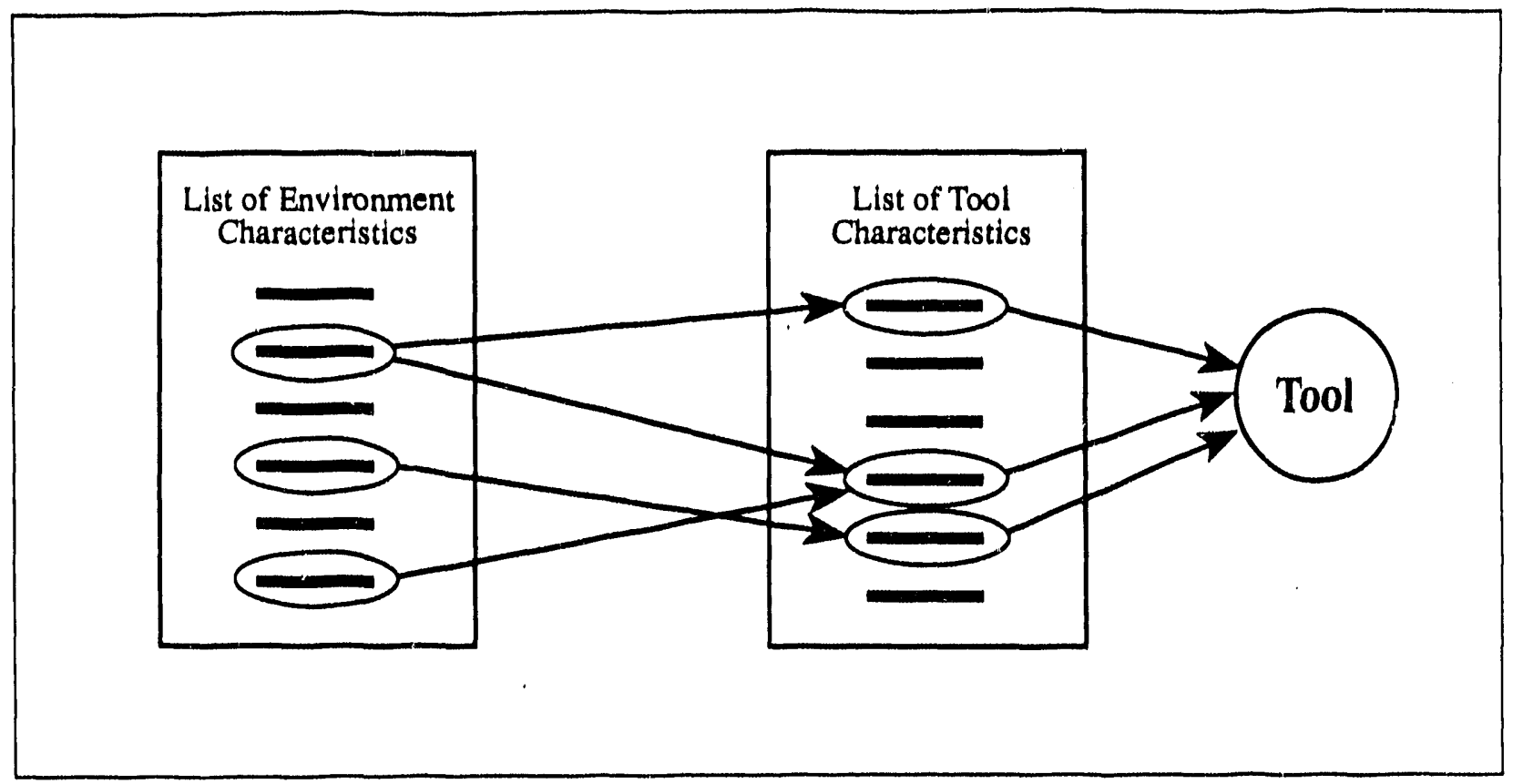

Figure II.B.2. The effectiveness of tools in reducing brushfires should improve as a result of mapping problem domain and tool characteristics and using that information as a design criterion to tool development. 
This page intentionally left blank. 


\section{II.B.3. IMPROVING THE SOFTWARE DEVELOPMENT PROCESS FOR CREATING MANAGEMENT TOOLS}

\section{a. Study Area Leader(s)}

Howard Swingle

Sheila Winett

\section{b. Description of Study Area}

Managers need the right management tools at the right time to respond effectively to the challenges placed on the organization. If the development of management tools cannot keep pace with the changing environment, the tools become outdated and worthless. If the tools are available in time but are prone to errors or need frequent maintenance, they are also useless. These problems with developing management tools can impede the continuous improvement of the organization.

Research in this study area will focus on the software development process used to create and improve management tools. We will study the effects of using different software development methodologies and tools on the speed and quality of the software development process. We will also study whether organizing software development teams in different work configurations affects the speed with which tools can be developed or the quality of the products. As a result of our research, we expect to affect the quality of tools available to managers and the speed with which those tools can be produced.

We chose Department of Energy (DOE) managers for our research on improving the software development process because it is an organization that is changing rapidly and is having new demands placed on it daily. As a result, its managers need tools developed quickly, so research in this study area is greatly needed.

For example, DOE maragers must answer questions from many constituents, including the Congress, executive branch agencies, and the Department of Defense. These managers must also analyze complex data quickly and consider many "unknowns" in their analyses. They require tools to accomplish thuse tasks. In today's environment, especially in the area of nuclear materials management, the number of questions being asked is increasing and the types of questions being asked are changing frequently. Given the major changes in the world situation, managers involved with nuclear materials management are faced with new challenges everyday. These managers need the right tools at the right time.

Our research in this study area will aim to identify factors that van speed up the tool development process.

Consequently, we expect to be able to provide DOE managers with better tools faster. We expect that the availability of those tools will allow managers to perform more effectively and will lead to continuous performance improvement in the organization. 


\section{c. Relationship to the Research Conceptual Model}

As Figure II.A indicates, managers use management tools to impact the organization. Using management methods and feedback about the performance of the organization, managers decide what tools are needed to help them manage and minimize the brushfires that divert their time from building the business. To continuously improve the organization, the managers' tools must be created or improved quickly to keep up with changing demands. Having the right tool at the right time will reduce the effects of brushfires and allow for continuous improvement.

\section{d. Accomplishments}

During the first grant year, we have identified DP-27, the branch responsible for nuclear materials management, as a part of DOE that would be an appropriate site for this research because it is experiencing rapid change. We have observed managers in DP-27 to learn about the piessures they are experiencing and the brushfires they must fight. We have identified the types of questions that are being asked, the processes and tools being used to answer these questions, and the constraints placed on managers in answering these questions. From these observations, we have identified enhancements needed to existing management tools and new tools that may be useful. As we study these enhancements and develop these new tools, we will have opportunities to collect data about our software development process and its effects on the speed with which we can develop tools and the quality of the products.
We are evaluating new software development methodologies and tools for creating and enhancing management tools. We are implementing the object oriented paradigm (OOP) of design and programming. We will assess whether using that paradigm improves the quality of our tools and reduces the software development time. We have used OOP to design and develop a new version of the tritium Personal Computer Master Nuclear Schedule (PC-MNS).

We have implemented a version control system in our development group to manage the large amounts of computer code used to create the management tools. We expect to investigate whether this system increases the integrity of our code versions. We may also use the data from the version control system to track the number of times a piece of code has to be modified. This data will serve as one possible indicator of software quality.

We have implemented the "functional prototyping" software development methodology. By producing prototypes, we can get a tool to the manager and get immediate feedback on its features. We can then use that data to guide development of improvements managers need. This process is iterative and involves the manager in the research and development of the management tool. We have used this methodology for developing several tools: one that helps managers study the feasibility of various stockpile conversion scenarios, the latest version of a database tool that is used to manage congressional questions and answers, the latest version of the Savannah River Spreadsheet, a tool that allows comparisons of tritium PC-MNS analyses, a version of the Savannah River Recovery Model that performs plutonium analyses, a version of the 
plutonium PC-MNS spreadsheet, a version of the uranium PC-MNS that has new algorithms and features to separately account for material not immediately reclaimed, and, a tool that helps managers create the Uranium Strategic Materials Plan. We will observe whether using this methodology gets management tools in managers' hands quicker.

In addition to informally experimenting with several new development methods, we have identified questions that will guide us in developing our research in this study area during the second year of the grant. The following are some potential research questions:

What software development tools are effective for developing management tools in a rapidly changing environment?

Do version control systems reduce software development time?

Do Local Area Networks (LANs) improve the software development process?

Is the functional prototyping methodology of software development quicker than a traditional method, such as the waterfall model?

Are object-oriented software development methods appropriate for keeping up with a manager's needs in a rapidly changing environment?

What organization of the software development team is appropriate for speeding up the tool development process?

What are the impicts of different tools for developing software with respect to the developer's learning curve, development time, system performance, portability, and user-friendliness?

Are management tools created with offthe-shelf packages better than customized tools in a rapidly changing environment?

We expect to continue experimenting with a variety of software development methodologies and observing DP managers through the rest of the grant year. We will use our results and observations to refine our research questions and define our research plans for subsequent grant years. 
This page intentionally left blank. 


\section{II.B.4. RECRUITMENT AND PROFESSIONAL DEVELOPMENT}

\section{a. Study Area Leader(s)}

\section{Marci Murawski \\ Ellen Tomchin}

\section{b. Description of Study Area}

Effective recruitment and professional development are critical to the continuous improvement of the organization. Selection of technical managers with strong communication skills, academic diversity, intrinsic motivation, and interests :ompatible with an organization's mission underlies the continuous improvement of the organization. To meet these recruitment goals, managers need the right tools to assist them in the recruitment process. Our reseurch will include the research and development of such tools and focus on providing tools to facilitate the professional development of individuals within Defense Programs (DP).

Once individuals are hired, training can facilitate the effective and efficient implementation of the management process needed for continuous improvement. Within the DP organization, the development of interns' and incumbents' technical and management skills is critical to the maintenance of a cadre of qualified technical managers prepared to oversee DP's complex facilities. Managers must have common understandings in technical disciplines and management issues to facilitate continued improvement and foster a culture of technical competence. For example, managers must know what to look for (anticipate problems), recognize oversights and errors, identify performance indicators, know what to do, how to do it, and know when they have done it well. Managel $i$ must also understand the system (i.e., the relationship between decisions and the effects of those decisions on all components of the system). Training managers to recognize and build on the interrelatedness of components within the organization can enhance organizational performance.

Furthermore, managers must be able to apply relevant problem-solving strategies for decision making. Thus, the training needs of an organization as complex as DP are many and varied. To meet the training goals, managers need the appropriate tools to assist them throughout the training process from determining the specific training needs to implementing and evaluating a training program.

The focus of the recruitment and professional development area of this grant is on determining, through a variety of research studies, an appropriate set of tools to be used by managers in hiring and training activities, and hence improving the processes of recruitment and professional development. The nine management methods and the corresponding rules serve as a basis for the design criteria which are being investigated.

\section{c. Relationship to the Research Conceptual Model}

As the research conceptual model shown in Figure II.A indicates, this grant examines the relationship between 
management tools and performance of an organizational component, as well as the continuous performance improvement of the organization as a whole. Research in the recruitment and professional development area focuses on improving the recruitment and professional development components of the organization by implementing and improving the Technical Training Management System for recruitment and professional development, illustrated in Figure II.B.4. Appropriate management tools are necessary within and among the various components to implement the system as well as to provide a means to assess its performance. Our efforts in this area focus on determining the appropriate design criteria for the tools used throughout the processes of hiring and training managers for DP. As the arrows suggest, the development and implementation of the appropriate tools comprising the Technical Training Management System is an interdependent and iterative process. Feedback through data collection and evaluation recurs and provides bases for changes in several components-Training System Plans, Career Planning, and Technical Training. The Training System Plans document the entire Technical Training Management System and drive Career Planning and Technical Training. However, effective plans cannot be developed in isolation, and therefore, Consensus Working Groups affect the design and optimal use of the Technical Training Management System. Evaluation is ongoing. Throughout this grant, we will collect data on each component of the Technical Training Management System, the processes used, the impact on the management process, and subsequently the impact on the continuous improvement of the organization.

\section{d. Accomplishments}

We have begun to collect data in each of the components comprising the Technical Training Management System for recruitment and professional development.

\section{Consensus Working Groups}

As DP restructures its training system for interns and incumbents to ensure a continued human resource of highly qualified engineers and scientists, DP needs a training management system common to headquarters and field offices. Consensus Working Groups offer a means of articulating training needs and sharing concerns between field offices and headquarters. During this grant year we participated in a consensus working group retreat. The purpose of this retreat was two-fold: 1) to share information about existing training programs and the internship program and 2) to identify common training problems and discuss means of communicating between field offices and headquarters. A follow-up survey of participants is planned to identify common and dissonant needs of field office and headquarters-based training programs and to assess both the shortterm and long-term value of such sessions. Responses to the survey will be analyzed during the remainder of the first grant year.

\section{Training System Plans}

The Training System Plans provide a blueprint for organizational implementation of training, outlining roles and responsibilities and thereby serving as a vehicle for implementing Career Planning and Technical Training. Work on the development of Training System Plans for DP was initiated in the 
first grant vear. In fall 1991, we made modifications in the Defense Programs Career Intern Program. We determined appropriate recruitment criteria and designed an effective recruitment process. Once we established the criteria and process, we developed management tools to facilitate these aspects of recruitment and prototyped a recruitment selection form. We used feedback from recruiters to revise forms used in the next recruiting cycle. We also developed initial interview and second interview protocols and designed a panel interview process for the second interviews. With this process we also developed individual and group rating forms. A modified version of this process was used later to conduct inplant interviews. We also developed an evaluation tool to assess the effectiveness of the recruitment process from the view of prospective interns. Assessments of the recruitment process and recruitment tools will be ongoing through the remainder of the first grant year and will provide feedback so improvements can be made.

\section{Career Planning}

The Training System Plans outline the career paths individuals may follow, providing options for the sequencing of training and rotational assignments. Prototypes of individual career (professional development) plans were developed and will be revised based on feedback. We have begun to collect data to research the impact of career plans on individuals, examining relationships between factors such as career satisfaction, attrition, and promotion rates. Career Planning as a component within the Technical Training Management System will be evaluated to determine its impact on the continued improvement of the organization.
Technical Training

To promote the technical proficiency of its engineers and scientists to meet the challenges of managing complex facilities into the 21 st century, DP will need to develop Technical Training courses for both interns and incumbents. During the first grant year we designed a set of Instructional Material Guidelines for development of technical courses. The emphasis on higher-order thinking skills, critical for highly technical problem solving, distinguishes these guidelines from other existing guidelines. During the remainder of the first grant year we plan to research these guidelines through a case study analysis. We plan to develop technical materials using the methods outlined and collect data as an instructor uses them in a training situation. Data collection will focus on determining the number and types of variations the instructor uses. We will also interview instructors to gather their perceptions of the value of the guidelines.

During this grant year we revised an instructional tool, the Nuclear Fuel Cycle Handbook. This handbook was designed to be used as a self-contained instructional module covering the basics of the nuclear fuel cycle and serving as a reference source for future study. We plan to examine the effectiveness of this tool when it is used during the 1992 Intern Orientation Program and make revisions based on feedback.

Evaluation

Evaluation will be a continuous process as DP restructures and expands its training system. To appropriately assess each component of the system, we will research, select, and develop evaluation tools to gather information needed for decision making. During this grant year, 
we conducted a formal evaluation assessing the Intern Orientation Program. We analyzed data from the 1991 Intern Orientation, and delivered a final report assessing the progress toward implementing recommendations from the 1990 evaluation. These findings will be examined in conjunction with findings from future classes to provide feedback for revision of the Orientation Program and its role in the training system. Throughout the process, we will also research evaluation methods for collecting and triangulating evaluation data from various sources.

\section{Technical Training Management System}

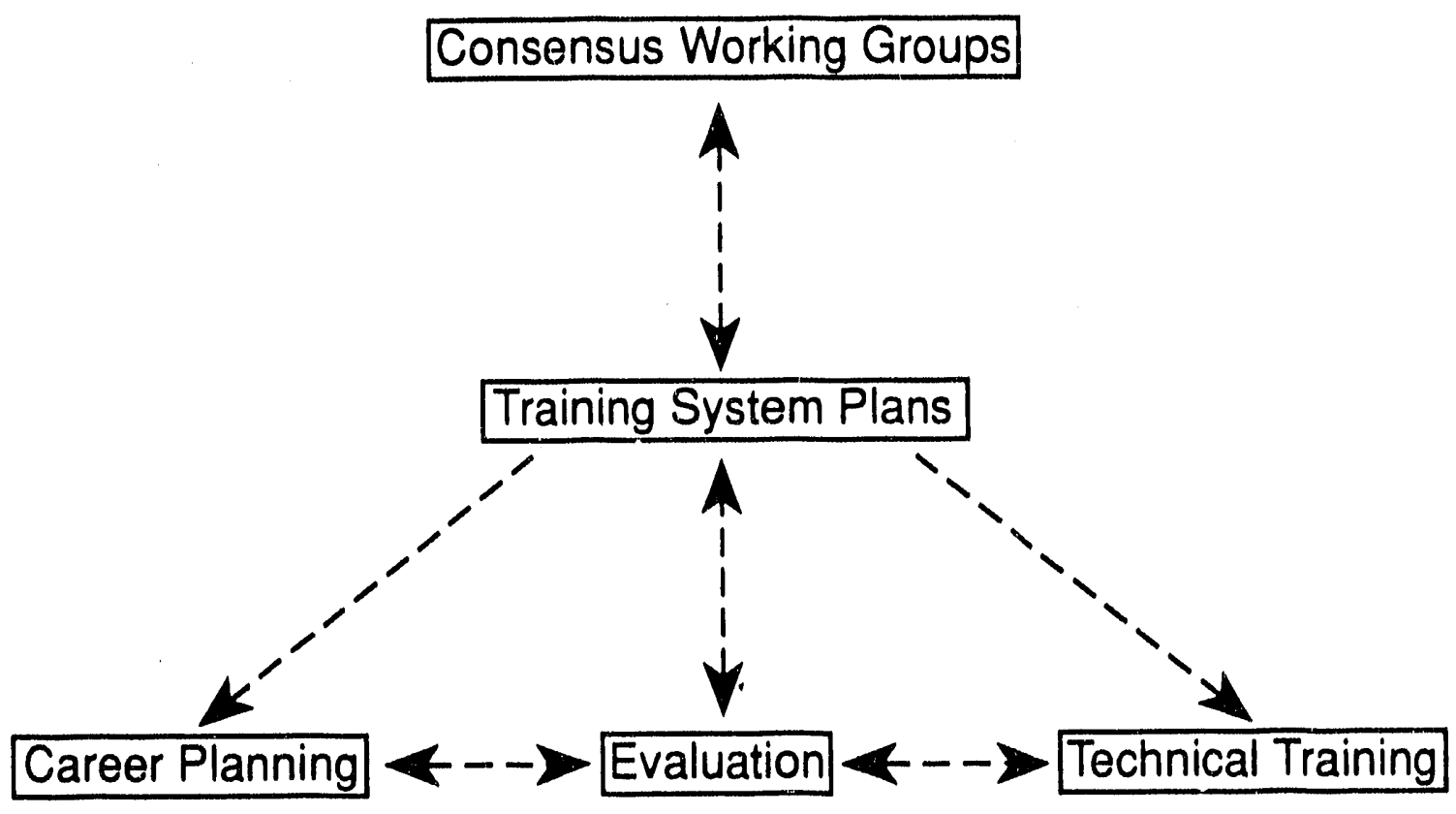

Figure II.B.4.

The Technical Training Management System consists of five interrelated components: Consensus Working Groups, Training System Plans, Career Planning, Technical Training, and Evaluation. Its implementation and the evaluation of its impact on organizational performance requires the development, use, and evaluation of appropriate management tools for recruitment and professional development. 


\section{II.B.5. CRISIS MANAGEMENT}

\section{a. Study Area Leader(s)}

Bradley Eichorst

Jyl Smithson-Riehl

\section{b. Description of Study Area}

Of all the disruptions or brushfires that any organization must confront, the most serious are crisis conditions resulting in events that pose a danger to the health or safety of personnel or the public or are a threat to the protection of property or the environment. We characterize such an event as an emergency. Management of an emergency requires unique tools, methods, and rules since managers cannot know in advance what, when, where, or how serious it may be. Emergency managers therefore must prepare for, respond to, recover from, and mitigate the most uncertain types of disruptions an organization can face. Uncertainty is the ratio of the information managers need to the information they have (Galbraith, 1973). In order to reduce uncertainty, large organizations identify and exert control over the potential for crisis conditions and also develop strategies and tactics for managing emergency events.

Some organizations anticipate emergencies by providing ongoing emergency operations for management. The director of emergency operations (DEO) assesses that some crisis circumstance could lead to an emergency event, and then the DEO safeguards, plans, gathers resources, trains, and exercises for those possible circumstances, such as a hazardous materials release, a terrorist attack, a computer crime, a radiological incident, or some other plausible crisis scenario. The DEO anticipates emergencies by forecasting a set of possible problems, then supports the development of organizational response resources based on plausible solutions to those problems.

Successful emergency management within today's complex organizations depends upon management tools. Based on the criteria derived from the management methods and rules, we will develop tools to uniquely suit requirements for anticipating, safeguarding against, and managing illdefined crisis conditions. We will collect data to determine whether these tools enable the DEO to more effectively reduce uncertainty. When an emergency does occur, the DEO must develop significant information on the type, severity, and scope of the crisis before the manager can begin to activate the appropriate emergency response elements. Turning emergencies as quickly as possible into manageable problems is what emergency operations is about. In crisis situations the DEO works to identify an emergency event and then achieve an acceptable outcome that, hopefully, has already been anticipated and prepared for. To gain control by turning uncertainty into more certainty, management of emergency operations must be based upon 1) an extensive preparedness platform, 2) rich information resources, and 3 ) a controllable decision environment. All of these assets must be in place to support emergency operations before any crisis occurs. 


\section{c. Relationship to the Research Conceptual Model}

We are researching and developing a unique set of emergency management tools to support the Department of Energy (DOE) in achieving better control of emergencies. Figure II.B.5 shows how we develop unique tools for emergency management. These tools are not only based upon sound design criteria (derived from the methods and rules), but also are developed on the basis of information we determine about the specific needs and conditions affecting particular DOE program offices. The capabilities of the tools may be evaluated during real or simulated crisis management, as illustrated by the feedback loops in the figure. We will study how the use of the nine management methods with their rules as design criteria for emergency management tools affects the performance of the tools and in turn the overall performance of the organization.

\section{d. Accomplishments}

We observed the DOE director of emergency operations to investigate and determine DOE needs for plan development, implementation, training, testing, and evaluation of emergency management tools. We designed plans and procedures for various headquarters (HQ) program offices, as selected by the $\mathrm{DEO}$, in order to provide for program office integration with the DOE complex-wide Emergency Management System (EMS) requirements and guidelines. We researched, developed, and implemented emergency management plans or revised plans to six program offices. We supported plan implementation by developing training for affected program office Emergency Management Team (EMT) cadres. We designed and delivered training packages to several DOE program offices.

Our research objective is to study whether unique tools in the form of plans, procedures, and training increase the effectiveness of the DOE EMS. We will determine whether increased effectiveness of the EMS can be measured through evaluating EMT performance during drills and exercises. We have hypothesized that increasing the frequency of training given to $\mathrm{HQ}$ EMT cadres will result in less time required to reach effective response management decisions. During the first reporting period, we have focused our efforts on gathering data to determine what will constitute effective management decisions in headquarterslevel emergency responses.

We have also hypothesized that, for administrative support personnel assigned from a program office to an EMT cadre, one-on-one performancebased training in operational settings is more effective than group performancebased training involving entire EMT cadres for developing the abilities of individual EMT administrative support personnel to accomplish designated role objectives. During the first reporting period we gathered preliminary data so we can identify and profile administrative support roles and requirements within current operational EMT configurations for $\mathrm{HQ}$ program offices.

We have hypothesized that designing and conducting a multi-tiered tabletop exercise program involving a DOE HQ program office, DOE Field Elements, and a DOE contractor-managed site will test the compatibility of interlocking emergency response plans and procedures throughout the complex-wide 
EMS. During the first reporting period, we developed the Energy Research (ER) multi-tiered tabletop exercise involving the ER Operational Emergency Management Team, DOE Field Office Chicago, and Argonne National Laboratory. The exercise, conducted in October 1991, yielded performance and outcome data for later analysis.

We have also developed a research question concerning risks that may result in crisis conditions: Can organizations successfully implement a management system for managing the risks associated with plausible crisis conditions in order to prevent or minimize the occurrence of emergency events? During this first reporting period, we have completed a risk management literature search in order to develop a baseline for risk investigations. We completed the risk management literature search and wrote the report as of December 1991. We developed hypotheses for integrating risk management into an EMS.

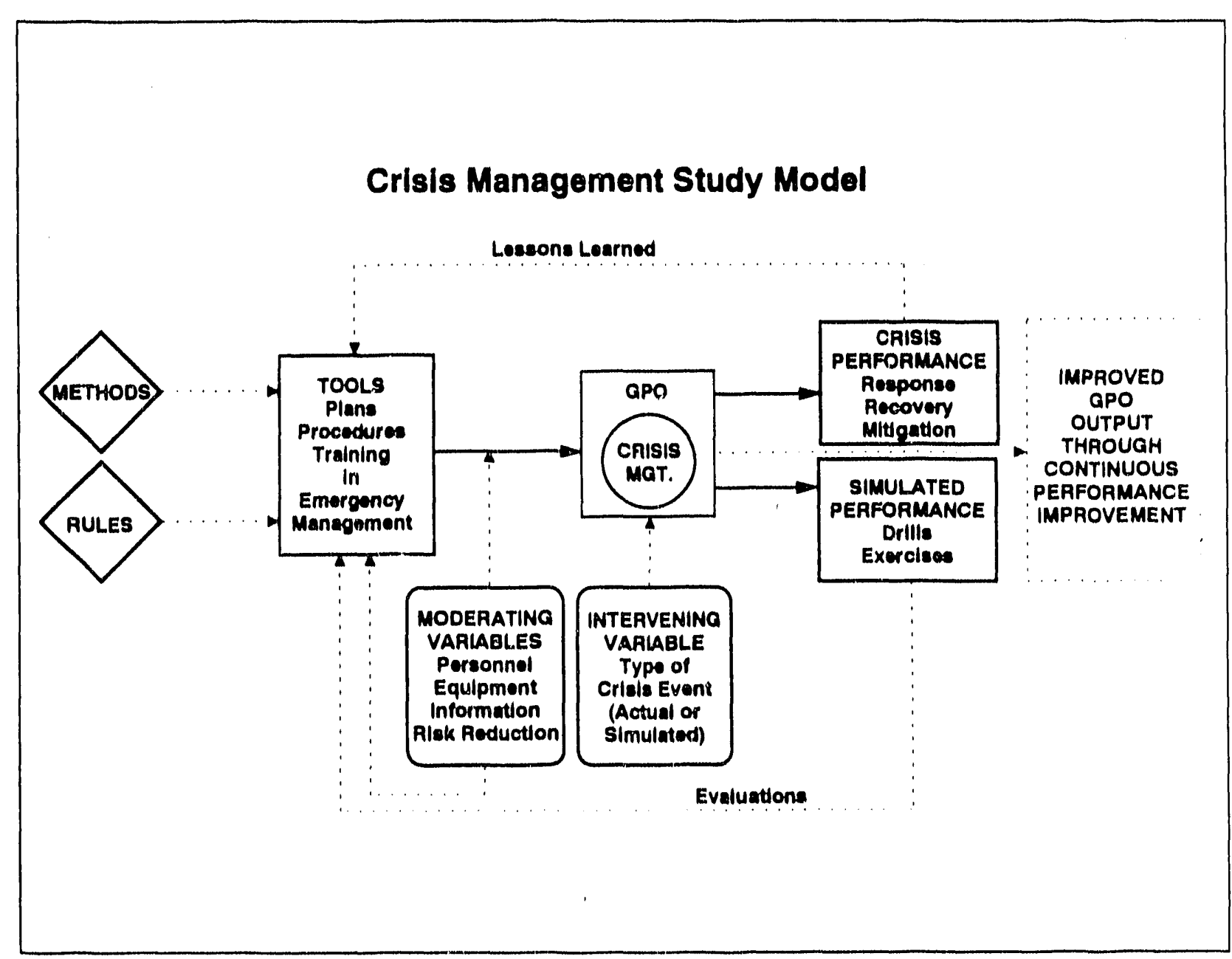

Figure II.B.5

Using unique tools designed for emergency management will permit managers to more quickly gain control of crises and spend more of their time improving the performance of the organization. 
This page intentionally left blank. 


\section{II.B.6. CULTURE MANAGEMENT}

\section{a. Study Area Loader(s)}

Brian Kleiner

Harold Kurstedt

Larry Mallak

Ulrike Zirner

\section{b. Description of Study Area}

Employees who are new to government program offices (GPOs) may encounter problems in adjusting to the new culture and turn to their manager for help. Employees' difficulties in dealing with the culture they work in can arise unexpectedly, demand immediate attention, preempt managers from normal duties, unnecessarily attract outsiders' attention, and destabilize an existing or past condition. In other words, these employee difficulties become brushfires demanding management attention and time.

Since adjustment can be viewed as a process, a control chart log can be used to show adjustment over time. By deriving control limits, strategies can be developed to focus on maladjustment above and below the control limits and different strategies can focus on continual improvement when the employee is adjusting within a normal range of variability. Using developed management tools, the manager can determine what caused different levels of adjustment. The manager can list possible adjustment problems for the various conditions and use the information as the basis of decisions for how to improve the adjustment of employees. By taking action, the manager will be able to increase the rate of adjustment which will, in turn, allow employees to perform in their new roles much faster.

Managers and researchers see organizational culture as a valuable construct targeting change efforts to produce outcomes ranging from happier workers to improved bottom-line performance. But much, if not most, of the work on culture has been theoretical and conceptual. People speak of strong cultures, rites, ceremonies, organizational stories, and more without a strong empirical basis for relating changes to organizational outcomes.

To reduce the amount of time managers spend managing brushfires, they need to be able to detect and prevent employee problems in adjusting to the new culture before such problems become brushfires. To do this, managers need management tools. In this study area, management tools will be developed to help managers detect employee problems in dealing with the new culture and thus, prevent brushfires and allow continuous performance improvement in the GPO.

\section{c. Relationship to the Research Conceptual Model}

A number of practical objectives of the Defense Programs (DP) grant relate to researching and developing management tools to reduce the impact of externallycaused brushfires and to reduce the number and impact of internally-induced brushfires. Managers need specially designed tools to improve the adjustment of their new employees so they can improve performance. 
However, managers have poor visibility of new employee adjustment. That is, they know little about the causes of poor adjustment. To start gaining visibility, managers need to collect and measure data relating to the adjustment process. Managers can do this by utilizing management tools based on design criteria derived from the management methods and rules as outlined in the research conceptual model in Figure II.A.

Typical models associating cultural strength and organizational performance treat cultural strength as a trait and adopt what Saffold (1988) calls the "trait-strength" framework. The traitstrength framework claims enhancements in organizational performance are related proportionately to the strength with which particular cultural traits are manifested. A management tool that will help GPO managers is a method for measuring cultural strength allowing managers to investigate the nature and extent of culture-performance links. In the research conceptual model (see Figure II.A) culture management is one component within the GPO box, and tools based on the management methods and rules are needed to measure and manage the GPO culture allowing feedback for continuous improvement.

\section{d. Accomplishments}

In February, we completed an extensive literature review based on over 300 articles, books, book chapters, and other sources. We found few empirical studies done on organizational culture. We first surveyed the literature highlighting culture-performance links, culture assessment instruments, and conceptual frameworl: for researching culture. The review surtused two basic approaches researchers take in organizational culture--functional and interpretive. Approaches aimed at the understanding and improvement of management processes, such as the present effort, tend to take a functional approach to the work. Alvesson (1990) labels functional approaches such as ours as "academic-pragmatic," meaning we maintain academic standards while producing knowledge that translates into usable management processes and tools.

To study culture management issues within GPOs, we have outlined our research hypotheses. GPOs, like other complex organizations, are confronted with unforeseen problems when a new employee enters the new culture. The adjustment process, like culture itself, can be managed, controlled, and improved. Management tools can be developed to help the GPO manager manage the culture and the employees' adjustment process.

Our research questions in this study area are as follows: What are the possible problems an employee may encounter when surrounded by a new culture? What effects do adjustment problems have on performance? What is meant by strength of an organization's culture and how can it be measured? Future work relating to these research questions will be divided into two modules. 


\section{II.B.7. MANAGER/MANAGEMENT TOOLS INTERFACE}

\section{a. Study Area Leader(s)}

Brain Kleiner

David Hill

\section{b. Description of Study Area}

In an organization, "ideal quality management" is defined as a manager's beliefs concerning what quality management should be, while "actual quality management" is defined as a manager's perceptions of the current practice (Benson, Saraph, and Schroeder, 1991). One of the means to reduce any gap between ideal and actual is to focus on improving the processes of the organization by researching methods and rules which serve as the basis for developing tools for managing better. Kurstedt (1991) defines management as "decision making" and portrays those who make decisions (virtually anyone in the organization) as carrying out a management process. This is consistent with Deming's (1986) definition that "management is prediction." Kurstedt (1985) portrays the manager's domain in the Management System Model (MSM) which defines the interaction between "who manages," "what is used to manage," and "what is managed." "Who manages" is the component referring to the human decision maker or predictor. Managers use a complex set of management tools ("what is used to manage") to help predict and make decisions. Success will depend on how well these management system components are balanced at the interfaces. More specifically, certain management tools can be designed to improve the overall management process.

Human factors engineering has had broad applications in the nuclear industry, Department of Defense, and various manufacturing domains. It is informative to understand the design of management tools from a human factors engineering perspective. This approach is predicated upon the premise that most system failures do not occur because of human error or shortcomings, but rather because of mismatches between human capabilities and system demands (Drury, Czaja, and Shealy, 1980). Deming (1986) stresses the total system. Likewise, when viewing human performance in the context of systems, the overall goal should be optimization of the system rather than any particular subsystem. This study area will develop and test a management process improvement system, including the research and development of one of the nine management methods, charting.

\section{c. Relationship to the Research Conceptual Model}

The research conceptual model focuses on using design criteria from the management methods and rules for developing management tools. In addition, this area of research will combine the methods and rules with a human factors approach to developing management tools. As illustrated in Figure II.B.7, a human factors engineering model views the total system as being composed of the human subsystem and the subsystem designed to support the human decision maker as 
well as the environment. With little modification, the model can be used to represent the interface between the human manager and the tools used by the manager.

The traditional manufacturing application of the model looks at the interaction between the human, machine, task, and environment. Our management systems application replaces the human operator with the manager or decis n-maker, the machine with "what is used to manage," and the task with the behavior of the manager. The environment extends to include the domain of the manager.

The concept of "task" exposes us to the methods used by human factors engineers and ergonomists to study the complex interaction between humans and the components of their working environment. Task analysis (e.g., Salvendy, 1987) is a step-by-step description of a task, followed by a more detailed task specification. The goals of task analysis include determining system demands relative to human capability, determining limiting subsystems, and adjusting the model in Figure II.B.7 to remove or reduce limitations. Such an approach is instrumental in designing management tools to improve a management process and the overall perfn:mance of the organization.

\section{d. Accomplishments}

We have identified our research hypotheses for this study area. They are 1) process improvement can be systematically accomplished by managers using properly designed methods and tools (e.g., charting), 2) a human factors engineering model can be used to effectively portray the design of management tools, and 3) process flow charts can be developed to complement technical and administrative procedures and vice versa.

In addition, we have outlined the following research questions: Can effective procedures be developed without first charting processes? Can procedures development be automated?

To study whether training improves the knowledge of an organization, we conducted a Process Development and Improvement Workshop for a new division in the Office of Nuclear Safety (NS). We collected data using both preand post-questionnaires. We also taped the workshop sessions so we can do protocol analyses of the interactions between new and more experienced employees. We will do this analysis during the remainder of the first year. We also began charting in NS to test some of our hypotheses and conducted a literature search. 


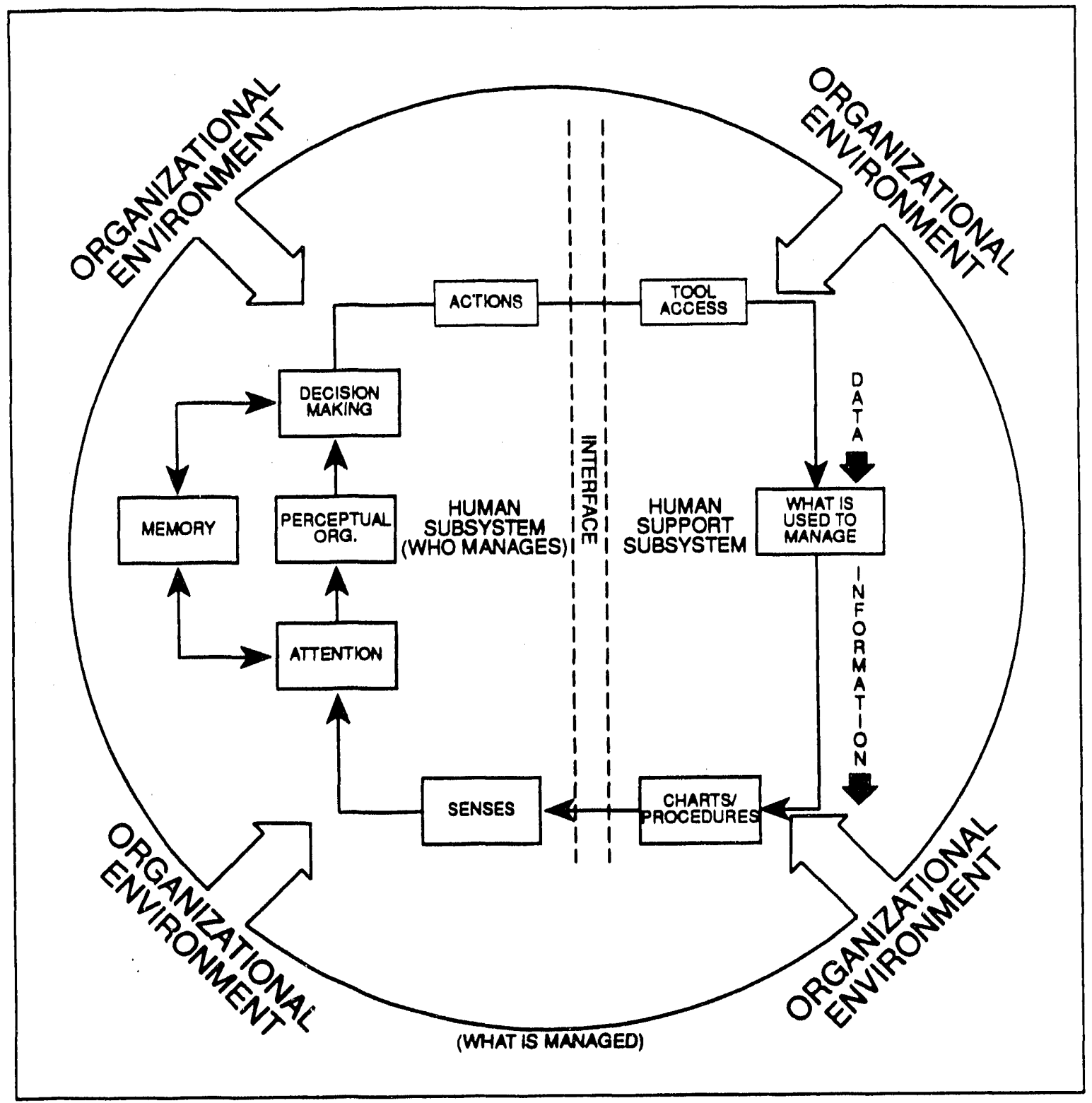

Figure II.B.7. It is important to apply a human factors view to a management system to understand the design of management tools. 
This page intentionally left blank. 


\section{II.B.8. STRATEGIC MANAGEMENT}

\section{a. Study Area Leader(s)}

Brian Kleiner

Dale Brubaker

\section{b. Description of Study Area}

Without a coordinated, systematic approach with efforts working synergistically, strategic planning and performance improvement activities tend to be unfocused, futile, and often counter-productive. Organizations need management tools to implement a strategic management process that provides structure for making decisions and taking actions, measuring and evaluating progress, and acting on the results for continuous improvement. Planning systems are management tools that enhance the way organizations plan, particularly for continuous improvement.

The structural elements of strategic planning that we focus on form a sevenstep process. This process includes: 1) defining the mission, 2) defining the vision, 3) defining the objectives, 4) analyzing the external environment, 5) analyzing the internal environment, 6) defining strategies and actions, and 7) defining feedback mechanisms. The mission defines the organization's purpose. The vision defines what the organization seeks to become and relates to the desired culture. The purpose of analyzing the external environment is to identify external threats and opportunities for the organization. Analyzing the internal environment identifies the strengths and weaknesses of the organization. Strategies are courses of action leading to the achievement of objectives through the use of tools and methods. Finally, feedback is received for continuous improvement. In fact, this seven-step strategic planning process is a cycle for continuous improvement. As an organization implements a strategic plan through methods and tools, corrective actions are made to keep the organization moving toward achievement of its objectives and the desired culture.

\section{c. Relationship to the Research Conceptual Model}

Within the government program office (GPO) box of the research conceptual model (Figure II.A) is a strategic planning component. In Figure II.B.8 we apply the Deming Plan-Do-Study-Act (PDSA) cycle to strategic planning. This cycle is closely tied to a consensus model, which can be used as a framework describing a systematic approach to strategic planning (or other group) meetings.

In the consensus model (see Figure II.B.8) the first part is the precipitator. The precipitating event/person motivates the need for strategic planning. For example the precipitator could be a threat to the company or an anticipated threat management wants to avoid. The purpose of a planning session is what managers hope to accomplish. Do managers want recommendations, a report, or actions carried out? In strategic planning you must know why you are bringing the people together.

Who should be included? Defining the people is the next step. Managers must 
have people involved who can guarantee that the purpose of the meeting is met. The next step is to define the problem or specific task the group will work on to derive the desired output.

One of the most important steps is defining the appropriate participation. Based on previous steps, managers have to decide if they want advice, information, consensus, etc. After the manager decides the expected or desired outcomes (purpose), who will be involved (people), the output expectations (problem), and a participation strategy, the manager must determine the process that will allow accomplishment of the desired results. The final step of the consensus model is the product or actual outcomes and outputs.

By using the consensus model to systematically define, isolate, and study each component of the Deming cycle, we hope to increase the effectiveness of the GPO strategic planning process. Strategic planning is most closely related to building the business and administering the management process. Therefore, if the effectiveness of planning can be increased, the amount of time managers cater to crises or put out brushfires will be less, allowing more time for building and improving the organization.

\section{d. Accomplishments}

GPOs, like other organizations, need more effective ways to do strategic planning. Before we could begin aiding the GPOs in their planning, we needed to define our research hypotheses. They scate: 1) a structured approach to strategic planning can be implemented within a GPO along with feedback for continual use and 2) if strategic planning is done more effectively, the amount of time managers spend responding to crises will be reduced.

The next step was to outline our research questions. This step resulted in the following two questions: Can an effective strategic planning process result in a more useful strategic plan? Can better strategic plans allow managers to respond more effectively to crises?

We have since accomplished some of our planned activities such as designing and facilitating both the Office of Nuclear Safety's (NS) Strategic Planning Retreat and a retreat for NS multi-year planning. We observed and collected data on these processes to study, evaluate, and make recommendations for improvement. We have also helped set up and facilitate the NS Quality Management Board and helped design an office manager position for NS nontechnical staff. 


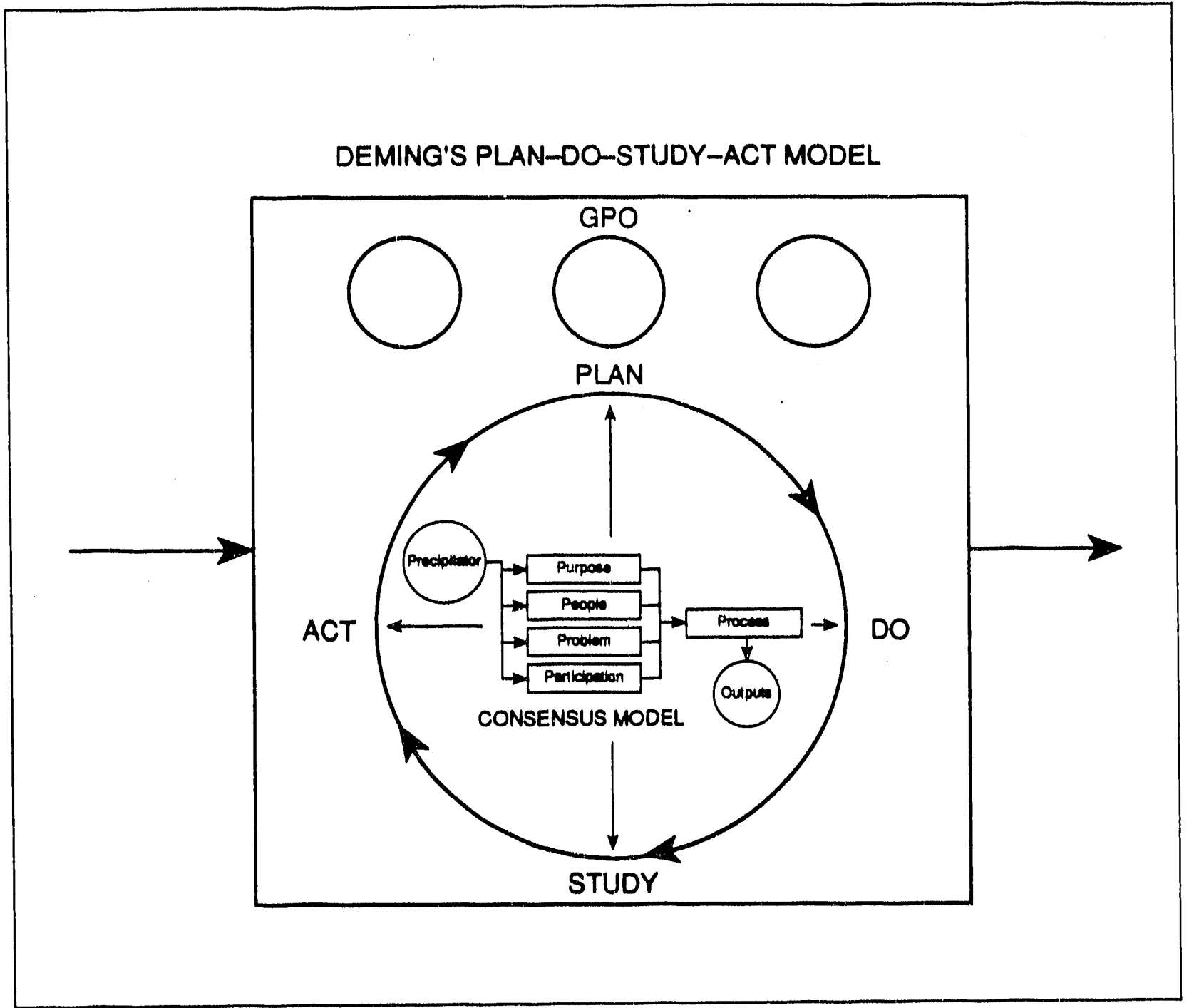

Figure II.B.8. The Deming PDSA Cycle can be combined with the consensus model to affect the strategic planning component within the GPO. 
This page intentionally left blank. 


\section{II.B.9. MANAGEMENT PROCESS}

\section{a. Study Area Loader(s)}

Brian Kleiner

George Stiles

John Merritt

\section{b. Description of Study Area}

This study area will focus on research related to using control charts (a management tool) to collect and keep track of process control data in a nonmanufacturing setting. Control charts have been an integral part of statistical process control efforts to improve manufacturing processes and produce higher quality products for a long time. However, in non-manufacturing settings control charts have traditionally been used sparingly.

In a non-manufacturing setting (e.g., a government program office (GPO), a bank, a hospital), processes are harder to define, and thus measurement is not as straightforward. This makes the use of control charts more difficult. If it could be done effectively, however, the results could be just as profound as they have been in manufacturing. Thus, this research will study how control charts can be applied in a GPO, as an example of a non-manufacturing setting, to help managers make appropriate decisions that will help improve the quality of the services they offer.

\section{c. Relationship to the Research Conceptual Model}

Logging is one of the closed set of management methods with their rules referenced in the research conceptual model (see Figure II.A). As the model indicates, using logs and the eight companion methods as part of a structured management process will contribute to the development of an integrated package of management tools to help a GPO gain visibility and control over brushfires. As a result, we expect the organization to continuously improve.

Control charts are a specific type of log that are directly applicable to the research conceptual model for this grant. This type of log is specifically designed to determine when a process is in control or out of control. By studying ways to successfully apply this method in a GPO, we would expect that managers will improve their management of externally-caused and internally-induced brushfires. Data from these charts will provide the basis for having managers make decisions about their domain. By letting managers know when their processes (their domain) are in control or out of control, we will enable them to take more appropriate actions. By doing this, managers can reduce the impact of brushfires and focus their activities on continuous improvement in the organization.

\section{d. Accomplishments}

We have defined our main research hypotheses for this study area: 1) management behaviors can be classified as part of common (system) strategies or special strategies and 2) control charts will aid managers in determining which strategies are appropriate for different situations. 
In addition, we have outlined the following research question for this study area: What factors contribute to a control chart's usefulness/effectiveness when applied to a non-manufacturing setting?
We have conducted a review of literature related to our research topic and are setting up specific research projects to test our hypotheses in the coming year. 


\section{II.B.10. RISK MANAGEMENT}

\section{a. Study Area Leader(s)}

Brian Kleiner

Dale Brubaker

\section{b. Description of Study Area}

The primary oversight goal of the Office of Nuclear Safety (NS) addresses the areas of risk reduction and effective residual risk management. This means the office oversees line organization programs that identify risks, compare risks, reduce risks, and manage residual risks. One way to contribute to this mission is for the oversight organization to define, identify, and assess a safety envelope for a nuclear facility. A safety envelope represents those characteristics and conditions of the nuclear facility that minimize risk to the workers, the public, and the environment.

This study area concerns the research and development of the safety envelope concept as it applies to government nuclear facilities. A literature review, together with consensus meetings using subject-matter experts, will help define the concept. Once the concept is fully defined, we will develop the process of oversight. A process development workshop will help oversight organizational personnel gain consensus on the issue. We will use flow charts as a tool to define, test, and modify the process. We will further support the process by procedures which will define a standardized assessment of the safety envelope for nuclear facilities. Both process and procedures will be developed within the framework of current Department of Energy policy and will be supported by principles put forth by the International Nuclear Safety Advisory Group (INSAG). By considering such elements as safety documents, and test results and operational history as part of a safety envelope, we will take a more systemic view of nuclear facilities and facility safety. A systemic view is clearly more conducive to providing stakeholders with an understanding of how and why safety is jeopardized when system limitations exceed system capability, Gaining such an understanding is critical to root cause identification and continuous improvement. For an oversight organization like NS, identifying specific deficiencies in conduct of facility management is important, but not as important as discovering and helping line management understand why those deficiencies exist. A systemic view through the concept of a safety envelope should help in this regard.

\section{c. Relationship to the Research Conceptual Model}

Within the government program office (GPO) organization box of the research conceptual model (Figure II.A) is a risk management component. Study of the safety envelope concept lies within the risk management component. Our research will determine the most effective way to apply the management methods, especially charting, to the development of management tools for risk management. Our area of study concerns the effectiveness of using charting to define processes and to develop procedures for assessing nuclear safety. 


\section{d. Accomplishments}

We have identified our research hypotheses which consists of two main statements: 1) an oversight GPO can maximize its effectiveness by taking a systemic view and 2) risk management can greatly be enhanced by the safety envelope concept.

In addition, we have outlined the following research questions: What is a universally understood and accepted definition of safety envelope? How can line organizations take a more systemic view of safety?

We have designed workshops to Implement charting techniques for process definitions. We are designing workshops to develop procedures based on these processes. 


\section{II.B.11. CRISIS MANAGEMENT IN PROJECTS}

\section{a. Study Area Leader(s)}

Harold Kurstedt

Gerold Patzak

Anil Swaml

\section{b. Description of Study Area}

This study only began in January 1992 and pertains to crises in projects. Project managers invariably experience crises during projects. This crisis could be a natural disaster, loss of equipment, resignation of personnel, war, and so on.

Small signals are often transmitted before a crisis occurs. This research will try to identify what those signals look like and what their characteristics are. The identification process is analogous to how a good maintenance engineer foretells the breakdown of a piece of machinery from the vibrations it emits before it breaks down. We will study the characteristics of these signals and develop a set of rules and procedures (tools) to identify them. To determine the characteristics of the signals, we will analyze historical and current projects. We will look for triggers or indicators that occurred before a crisis. This will help us develop a tool box for project managers to use to recognize the signals that occur before a crisis.

\section{c. Rolationship to the Research Conceptual Model}

As the research conceptual model shown in Figure II.A indicates, this grant examines the relationshlp between management tools and performance of an organizational component, as well as the continuous performance improvement of the organization as a whole. Developing a set of management tools and procedures for project managers to use in identifying crisis signals helps these managers do their jobs better. If managers are forewarned about the imminent occurrence of a crisis, they could prevent or manage it more effectively. Effectively managing brushfires allows these project managers more productive time with their work. This contributes to the continuous performance improvement of the organization as a whole.

\section{d. Accomplishments}

We are in the process of reviewing literature in three areas: project management, crises management, and early warning systems. We have also developed the draft research question: What rules (procedures) can a project manager use to be perceptive to the signals that are transmitted before a crisis occurs in a project? 
This page intentionally left blank. 


\section{III.}

Appendices 


\section{APPENDIX A: PAPERS AND PRESENTATTONS}

The listed papers and presentations were prepared as part of Manage inent Systems Laboratories' research during the first five months of grant year one of the DP Grant.

The papers were presented at various conferences and then published in conference proceedings. The presentations were given at a conference but were not published in the proceedings.

Title

$\underline{\text { Date }}$

Papers:

Asking the Right Questions: The Influence of Career Goals on Perception of Training.

American Evaluation Association Conference.

Developing an Integrated Risk Management System in

Emergency Management.

1991 Annual Meeting of the Society for Risk Management.

\section{Presentations:}

Myths in Applying TQM in Service Organizations.

Production and Operations Management Society 1991.

Experience in Installing a Management Process for Continuous Improvement in Service Operations.

Production and Operations Management Society 1991. 


\section{APPENDIX B: GRADUATE STUDENTS}

The following list represents graduate students who work under the grant and whose thesis/dissertation is related to the grant.

\begin{tabular}{|c|c|c|c|c|}
\hline Student & Degree & $\begin{array}{r}\text { Gra } \\
\underline{S t}\end{array}$ & $\begin{array}{l}\text { rant-year } \\
\text { Started }\end{array}$ & $\underline{\text { Status }}$ \\
\hline Larry Mallak & $\mathrm{PhD}$ & $\begin{array}{l}\text { Development, Application, And } \\
\text { Validation Of An Organizational } \\
\text { Assessment Instrument }\end{array}$ & 1 & $\begin{array}{l}\text { finishing } \\
\text { December } 1992\end{array}$ \\
\hline John Merritt & MS & $\begin{array}{l}\text { Factors Increasing The } \\
\text { Effectiveness Of Logs } \\
\text { As A Management Tool }\end{array}$ & 1 & $\begin{array}{l}\text { finishing } \\
\text { May } 1993\end{array}$ \\
\hline George Stiles & MS & $\begin{array}{l}\text { Development Of Decision Making } \\
\text { Strategies For Managers }\end{array}$ & 1 & $\begin{array}{l}\text { finishing } \\
\text { May } 1993\end{array}$ \\
\hline Anil Swami & MS & Crises in Project Management & 1 & $\begin{array}{l}\text { finishing } \\
\text { May } 1993\end{array}$ \\
\hline Ulrike Zirner & MS & $\begin{array}{l}\text { Development of Management Tools } \\
\text { to Enhance New Employees' Adjustme } \\
\text { to Culture }\end{array}$ & $\begin{array}{r}1 \\
\text { ent }\end{array}$ & $\begin{array}{l}\text { finishing } \\
\text { May } 1993\end{array}$ \\
\hline Jana Moore & $\mathrm{PhD}$ & $\begin{array}{l}\text { Decision Making in } \\
\text { Emergency Management }\end{array}$ & 1 & $\begin{array}{l}\text { since Jan } 1992, \\
\text { on leave of } \\
\text { absence }\end{array}$ \\
\hline
\end{tabular}

The following list represents graduate students who work under the grant but whose thesis/dissertation is not directly related to the grant.

\begin{tabular}{|c|c|c|c|}
\hline Student & & Grant-year & \\
\hline Student & Degree & & $\underline{\text { Status }}$ \\
\hline Todd Walsh & MS & 1 & $\begin{array}{l}\text { finishing } \\
\text { August } 1993\end{array}$ \\
\hline Gary Gilbert & MS & 1 & $\begin{array}{l}\text { finishing } \\
\text { May } 1993\end{array}$ \\
\hline Andy Hansbrough & MS & 1 & $\begin{array}{l}\text { finishing } \\
\text { May } 1993\end{array}$ \\
\hline Karen Krause & MBA & 1 & $\begin{array}{l}\text { finishing } \\
\text { May } 1993\end{array}$ \\
\hline Gilbert Lau & MS & 1 & $\begin{array}{l}\text { finishing } \\
\text { Decemher } 1992\end{array}$ \\
\hline
\end{tabular}


Amlan Mitra

Mary Jo Zukowski
MS

MS

1

1

finishing

May 1993

finishing

September 1993 


\section{APPENDIX C: WORKS CITED}

Alvesson, M. (1990). On the popularity of organizational culture. ACTA Sociological, vol. 33, 31-49.

Benson, P. G., Saraph, J. V., and Schroeder, R. G. (1991). The effects of organizational context on quality management: an empirical investigation. Management Science, vol. 27:9, 1107-1124.

Deal, T. E., and Kennedy, A. A. (1982). Corporate Cultures: The Rites and Rituals of Corporate Life. Reading, MA: Addison-Wesley Publishing Company.

Deming, W. E. (1986). Out of the Crisis. Cambridge, MA: MIT Center for Advanced Engineering.

Drury, C. G., Czaja, S. J., and Shealy, J. E. (1980). Ergonomics in Manufacturing. Buffalo, NY: University at Buffalo.

Drury, C. G., and Kleiner, B. M. (1990). Training in industrial environments. Proceedings of the 23rd Annual Conference of the Human Factors Association of Canada, 99-108.

Galbraith, J. (1973). Designing Complex Organizations. Reading, MA: AddisonWesley Publishing Company.

Kerr, J., and Slocum, J. W. (1987). Managing Corporate Culture Through Reward Systems. Academy of Management Executive, vol. 1, 99-108.

Kurstedt, H. A. (1991). Why the Methods for Management Will Work for You. Blacksburg, VA: Management Systems Laboratories.

Kurstedt, H. A, and Mallak, L. A. (1985). MIS success in a federal government organization. Proceedings Integrating People and Technology, 299-308.

Mendes, P. M. (1990). The Manager as a System's Controller: An Application of Management Systems Engineering Concepts. Unpublished doctoral dissertation, Virginia Polytechnic Institute and State University.

Saffold, G., III. (1988). Culture traits, strength, and organizational performance: moving beyond "strong" culture. Academy of Management Review, vol. 13, 546-558.

Salvendy, G. (1987). Handbook of Human Factors (ed.). New York: Wiley.

Schein, E. H. (1984). Coming to a new awareness of organizational culture. Sloan Management Review, Winter, 3-16.

Smircich, L. (1983). Concepts of Culture and Organizational Analysis. Administrative Science Quarterly, vol. 28, 339-358.

Trice, H. M., and Beyer, J. M. (1984). Studying Organizational Cultures Through Rites and Ceremonials. Academy of Management Review, vol. 9, 653-669. 

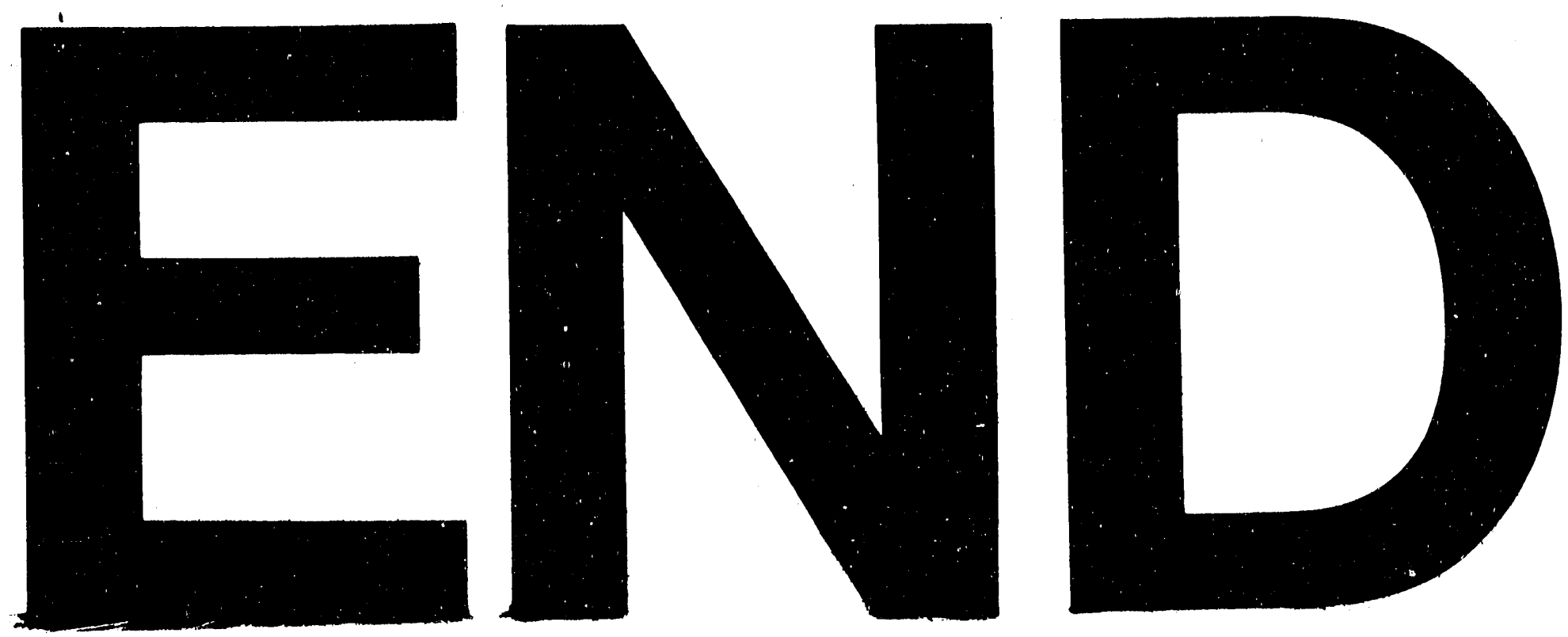

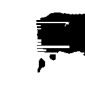
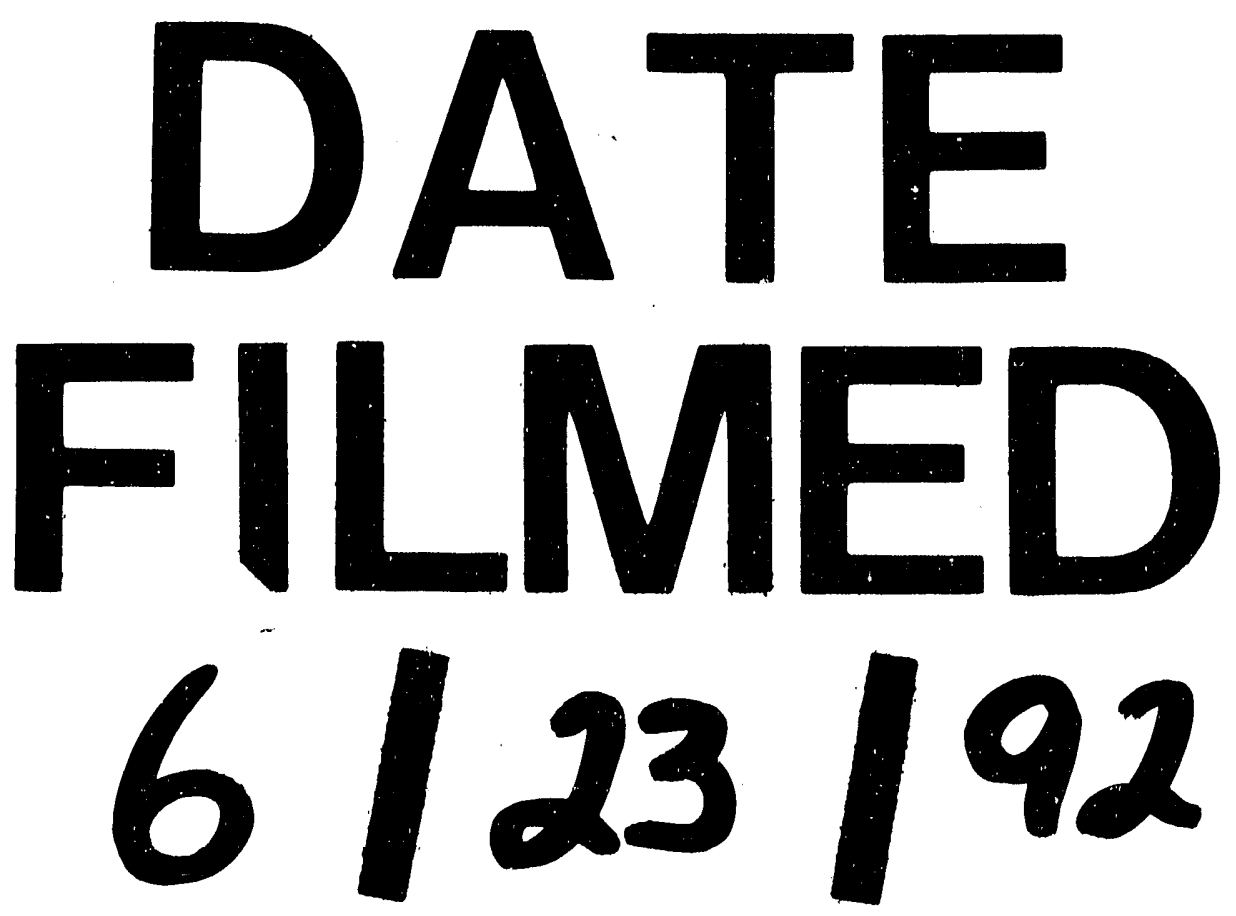

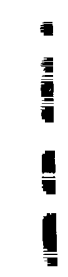


: 